The copyright of this thesis vests in the author. No quotation from it or information derived from it is to be published without full acknowledgement of the source. The thesis is to be used for private study or noncommercial research purposes only.

Published by the University of Cape Town (UCT) in terms of the non-exclusive license granted to UCT by the author. 


\title{
Industry Structure and Labour Market Flexibility in the South African Manufacturing Sector: A Time Series and Panel Data Approach
}

\author{
A. J. Hill ${ }^{\dagger}$
}

May 2007

\begin{abstract}
Our investigation of industry structure in South African manufacturing reveals evidence of imperfect competition. We find an average mark-up of $50 \%$ for the period 1970 to 2004 . Results suggest that there is no consistent trend in the mark-up over time. Extending this analysis, we find that two thirds of total labour employed in South African manufacturing is devoted to fixed costs. We find that this proportion falls during the 1980s and rises during the 1990s, suggesting an increase in labour flexibility followed by a decrease.
\end{abstract}

\footnotetext{
"This work has not been previously submitted in whole or in part for the award of any degree. Each significant contribution to this dissertation from the work of other people has been attributed.

'School of Economics, University of Cape Town. A mini-dissertation submitted in partial fulfilment of the requirements for the award of the degree of Master of Commerce in Economics.
} 


\section{Introduction}

There is a strong labour market debate in South Africa. This is because of its high rate of unemployment. A number of potential causes have been identified in the literature. Examples of these include the level of real wages (Fedderke et al (2000)), information asymmetries (Wittenberg (2002)), the impact of technology (Fedderke et al (2000)) and trade liberalization (Edwards (2001)). An important subtext of the debate is the degree of labour market flexibility. While an early study dismissed this as a potential cause of poor labour market performance, labour market flexibility has been indicated as a source of concern in South Africa. ${ }^{1}$

This paper makes two important contributions to the debate. First, it represents the first attempt (to the best of our knowledge) at numerically estimating the extent of labour market flexibility, by manufacturing sector, for South Africa. As such, it presents a series of time-varying numerical estimates of the extent of inflexibility in sectoral labour markets. Second, it provides the innovation of not isolating labour market conditions from market structure, but of intrinsically linking the two.

We investigate industry structure in South African manufacturing by analyzing mark-ups of prices over marginal cost under the consideration that the more competitive the market, the narrower the gap between prices and marginal cost. This is done for the manufacturing sector as a whole and individually for its twenty-eight sub-sectors in an analysis that extends from 1970 to 2004 . We establish average mark-ups for this period as well as investigating the trends and changes in mark-ups within this period, using both a computational approach and an econometric approach. Both approaches follow from a methodology developed by Roeger (1995).

Oliviera Martins and Scarpetta (1999) proposed an extension of Roeger's methodology that allows for the investigation of short-run dynamics in markups. They considered the possible impact of downward rigidities in the labour market through the inclusion of an additional labour adjustment parameter. This parameter can be interpreted as a measure of labour flexibility. We use our mark-up results to extract estimates of this parameter. As in the analysis of mark-ups, this is done for the manufacturing sector as a whole and individually for its twenty-eight sub-sectors. We also investigate both long-run means and trends and changes of this parameter over time.

${ }^{1}$ The early study referred to is Fallon and Lucas (1998). 
This paper extends the work of Fedderke et al (2006) by obtaining more recent estimates of mark-ups for South African manufacturing. The primary contribution of this paper, however, is the provision of a labour flexibility analysis in which we obtain numerical estimates of the magnitude of the flexibility and its changes.

Our paper is organized as follows: Section 2 provides details on the relationship between productivity residuals and the mark-up. It also shows how we analyze labour flexibility using the mark-up methodology and then overviews relevant previous empirical results. The econometric methodology is explained and justified in Section 3. Section 4 begins with a discussion of the data and then reports the results for the mark-up and labour flexibility analyses, respectively. Our concluding thoughts and remarks form Section 5 .

\section{Productivity Residuals and the Mark-up}

Hall (1990) finds a relation between the mark-up of prices over marginal cost and the Solow Residual $(S R)$. We derive this result from a production function $Q(K, L)=\Theta G(K, L)$, where $Q, K$ and $L$ denote value-added, capital and labour, respectively, $G$ is a nested production function and $\Theta$ is a technology parameter allowing for exogenous Hicks-neutral technological progress. Defining $w$ and $r$ as wage and rental respectively, and letting $\theta=\frac{\Delta \theta}{\Theta}$, an expression for marginal cost can be given by:

$$
M C=\frac{w \Delta L+r \Delta K}{\Delta Q-\theta Q}
$$

Re-arranging equation (1) and dividing by $Q$ allows us to obtain the following expression:

$$
\frac{\Delta Q}{Q}=\frac{w \Delta L}{M C \cdot Q}+\frac{r \Delta K}{M C \cdot Q}+\theta
$$

If we now define the mark-up of prices over marginal cost by $\mu=\frac{P}{M C}$, denote the factor share earned by labour by $\alpha=\frac{w L}{P Q}$, and let lower-case variables denote natural log transforms, we can re-write equation (2) under constant returns to scale as:

$$
\Delta q=\mu \alpha \Delta l+\mu(1-\alpha) \Delta k+\theta
$$


Simple manipulation of equation (3) then gives us Hall's result:

$$
\begin{aligned}
S R & =\Delta q-\alpha \Delta l-(1-\alpha) \Delta k \\
& =(\mu-1) \alpha(\Delta l-\Delta k)+\theta
\end{aligned}
$$

Estimation of equation (4) is not straightforward as the explanatory variable (the difference between labour growth and capital growth $(\Delta l-\Delta k)$ is likely to be correlated with the productivity shocks $\theta$. This will result in bias and inconsistency in the estimates of $\mu-1$. Hall's solution is to instrument. Instruments are required to be correlated with the factor inputs or output fluctuations, but not technological change, which is the error term $(\theta)$. In the case of applications to the US, instruments employed have been pure aggregate demand shifters. Hall (1990), for example, employs the variables military expenditure, the world oil price, and the political party of the president. He makes use of a variety of instruments as he recognizes that no single assumption about the relation between productivity growth and output fluctuations is likely to appeal to all schools of thought. Instrumentation for the US led to the estimation of mark-ups that often were argued to be implausibly high. ${ }^{2}$

Roeger (1995) solved the estimation problem by suggesting an alternative approach that avoids the need for instrumentation. By computing the dual of the Solow Residual $(D S R)$, we obtain a relation of the price-based productivity measure to the mark-up. This is given by:

$$
D S R=(\mu-1) \alpha(\Delta u-\Delta r)+\theta
$$

For reasons symmetrical to those surrounding equation (4), the explanatory variable (the difference between wage growth and rental growth) will continue to be correlated with technological change. Equation (5) is therefore subject to the same endogeneity problems as equation (4), again resulting in the need for instrumentation; the estimation biases associated with Hall's approach would then persist. Roeger's insight was that the subtraction of equation (5) from equation (4) would give us the nominal Solow residual $(N S R)$. This gives us the expression:

$$
\begin{aligned}
N S R & =\Delta(p+q)-\alpha \Delta(w+l)-(1-\alpha) \Delta(r+k) \\
& =(\mu-1) \alpha[\Delta(w+l)-\Delta(r+k)]
\end{aligned}
$$

${ }^{2}$ See Oliviera Martins and Scarpetta (1999) for a more detailed discussion of the potential for bias associated with instrumentation and Basu (1995) for bias associated with the omission of intermediate inputs. 
The productivity shocks $(\theta)$ have now cancelled out. As there is no longer a theoretical error term that is likely to be correlated with the explanatory variables, there is no need for instrumentation. Note that no additional biases are introduced by the subtraction as the mark-up $(\mu-1)$ obtained using the dual Solow residual (5) is theoretically equivalent to the mark-up obtained using the Solow residual (4).

The mark-up is now accessible to either estimation or computation.

While problems of endogeneity are addressed by equation (6), we have still imposed the assumption of constant returns to scale. This is naturally a problem in cases in which this assumption is not valid. Oliviera Martins and Scarpetta (1999) provide an alternative derivation in which the assumption of constant returns to scale is dropped. Their derivation begins with the definition of the margin between value-added and total costs given by:

$$
\frac{P Q}{w L+r K}=\frac{\mu}{\lambda}
$$

where all variables are defined as before and $\lambda$ is an index of the degree of returns to scale (i.e. $\frac{A C}{M C}$ ). Taking the total differential of equation (7) and dividing by $P Q$, we can re-write (7) as:

$$
\Delta(p+q)=\frac{\mu}{\lambda} \alpha \Delta(w+l)+\left(1-\frac{\mu}{\lambda} \alpha\right) \Delta(r+k)
$$

We can now re-arrange equation (8) to obtain an expression that is equivalent to equation (6), but where no assumption is made on the level of returns to scale. The new expression is:

$$
N S R=\left(\frac{\mu}{\lambda}-1\right) \alpha[\Delta(w+l)-\Delta(r+k)]
$$

where $\lambda>1$ denotes increasing returns to scale. ${ }^{3}$ Therefore any estimates of the mark-up that follow from equation (6) should be interpreted as lowerbound values under conditions of increasing returns to scale (and upperbound values under conditions of decreasing returns to scale).

There have been several other extensions within this methodological framework. Oliviera Martins and Scarpetta (1999) consider the impact of intermediate inputs and cyclical fluctuations in their analysis of mark-ups in the US manufacturing sector. Hakura (1998) looks at the impact of openness

${ }^{3}$ Equation (6) placed in this context that allows varying levels of the return to scale simply makes the assumption $\lambda=1$. 
on the mark-up. Fedderke et al (2006) consider the impact of market structure on the magnitude of mark-ups. These extensions introduce a variety of additional parameters and terms into the mark-up equation.

\subsection{The Mark-up and Labour Adjustment}

The above theory relating productivity residuals and the mark-up is based on a first-order approximation of the primal and dual Solow residuals. This is appropriate when estimating the steady-state mark-up. However it does not allow for the investigation of cyclical effects as these are second-order. An adaptation of a result derived by Oliviera Martins and Scarpetta (1999) shows us that under the condition of a two-input production function (where we ignore intermediate inputs) and with Hicks neutrality in technical progress, the equation for the variable mark-up is given by:

$$
\begin{aligned}
\Delta \log \mu= & (\Delta q+\Delta p)-\Delta w+\left(\frac{1}{\sigma}-1\right) \bar{\mu}(1-\alpha) \Delta k \\
& -\frac{1}{\sigma} \frac{L}{L-\bar{L}} \bar{\mu}(1-\alpha) \Delta l-\bar{\mu} \alpha \Delta l
\end{aligned}
$$

where $\sigma$ denotes the elasticity of substitution between capital and labour, $\bar{\mu}$ the steady-state mark-up and $\bar{L}$ the amount of labour devoted to fixed costs.

A generalization of the Oliviera Martins and Scarpetta (1999) result proceeds from the production function given by:

$$
Q(K, L-\bar{L})=\Theta G(K, L-\bar{L})
$$

where we assume the possibility of downward rigidities in the adjustment of labour inputs by introducing $\bar{L}$, the amount of labour devoted to fixed costs. (Also recall that $\Delta \log \Theta=\theta$.)

For a profit-maximizing firm under imperfect competition, the mark-up of prices over marginal cost is given by:

$$
\mu=\frac{\Theta G_{L}(K, L-\bar{L})}{W / P}
$$

where $\Theta G_{L}(K, L-\bar{L})$ denotes the marginal product of labour (the partial derivative of $Q(K, L-\bar{L})$ with respect to labour $){ }^{4}$

${ }^{4}$ Following Oliviera Martins and Scarpetta (1999) we have not accounted for the impact of capital on the mark-up at this stage. This is potentially a limiting assumption. 
We take logs and first differences to obtain the following expression for the growth rate of the mark-up:

$$
\Delta \log \mu=\theta-(\Delta w-\Delta p)+\frac{1}{G_{L}}\left(G_{L L} \Delta L+G_{L K} \Delta K\right)
$$

We can now use the established results that $G_{L L}=-G_{L K} \frac{K}{L-\bar{L}}, \sigma=\frac{G_{L} G_{K}}{G_{L K} G}$ (Uzawa, 1962) and $\frac{G_{K} K}{G}=\bar{\mu}(1-\alpha)$ to simplify this expression, obtaining:

$$
\Delta \log \mu=\theta-(\Delta w-\Delta p)+\frac{\bar{\mu}(1-\alpha)}{\sigma} \Delta k-\frac{\bar{\mu}(1-\alpha)}{\sigma} \frac{L}{L-\bar{L}} \Delta l
$$

It remains for the unobservable productivity term $\theta$ to be replaced by observable measures. We do this by obtaining an expression for the growth rate of real value-added from the original expression of the production function. Note that:

$$
\begin{aligned}
\frac{\Delta Q}{Q} & =\frac{(\Delta \Theta) G}{Q}+\frac{\Theta(\Delta G)}{Q} \\
& =\frac{\Delta \Theta}{\Theta}+\frac{\Theta G_{K} \Delta K}{Q}+\frac{\Theta G_{L} \Delta L}{Q}
\end{aligned}
$$
obtain:

We now use the first-order conditions $\frac{G_{K} K}{Q}=\frac{\bar{\mu}(1-\alpha)}{\theta}$ and $\frac{G_{L} L}{Q}=\frac{\bar{\mu} \alpha}{\theta}$ to

$$
\Delta q=\theta+\bar{\mu}(1-\alpha) \Delta k+\bar{\mu} \alpha \Delta l
$$

from which an expression for $\theta$ can be obtained and substituted into equation (14). This gives us equation (10).

The term $\frac{L}{L-\bar{L}}$ can be interpreted as an indicator of the degree of downward rigidities in labour adjustment. Its plausible range is from unity (indicating no rigidity) to infinity (complete rigidity). It is the ratio of total labour employed $(L)$ to the employed labour that is devoted to variable costs $(L-\bar{L})$. For example, a value of two means that of the total labour employed, half is devoted to fixed cost and half to variable cost.

Finally, we can re-arrange (10) to obtain the following expression:

$$
\begin{aligned}
& \frac{1}{1-\alpha}\left(\frac{\Delta \log \mu-((\Delta q+\Delta p)-\Delta w)}{\bar{\mu}}-\alpha \Delta l\right) \\
= & \left(\frac{1}{\sigma}-1\right) \Delta k-\frac{1}{\sigma} \frac{L}{L-\bar{L}} \Delta l
\end{aligned}
$$

which leads to the empirical specification that is employed in this study. 


\subsection{Previous Empirical Results}

We discuss three sets of literature: the first set concerns the development of the appropriate empirical methodology to estimate the mark-up of prices over marginal cost with emphasis on the associated estimation issues, the second set focuses the discussion on South Africa and looks at previous estimates of the mark-up obtained for South Africa as well the behaviour of the mark-up over time, and the third set concerns labour flexibility and adjustment in South Africa. We begin with the first set on the estimation of the mark-up.

The literature on the theory of industry structure, imperfect competition and the practical application of mark-up pricing begins with Hall and Hitch (1939). A significant contribution was made by McCallum (1970) who investigated the effect of demand on prices in British manufacturing in a critique of two earlier papers. ${ }^{5}$ The modern literature boasting a more credible estimation strategy begins with Hall (1990).

Hall (1990) decomposes the Solow residual (the difference between output growth and a weighted average of factor input growth) into a pure technology component and a mark-up component, observing that the degree to which price exceeds marginal cost can be estimated from this decomposition of the Solow residual. He finds a large gap between price and marginal cost (a positive mark-up) for many US industries, and suggests that this comes about through monopoly power in the product market. The methodology adopted by Hall (1990) requires the use of instrumental variables. Subsequent studies have found that these introduce upward biases in the estimates.

The Roeger (1995) methodology removes the dependence on instrumental variables through an insightful use of both the primal and dual Solow residuals. He finds that the difference between these two productivity measures is largely due to the presence of imperfect competition (price mark-ups) in the US manufacturing sector. Oliviera Martins and Scarpetta (1999) introduce the possibility of downward rigidities in the labour market and find mark-ups in the US manufacturing sector to be countercyclical. This is in contrast to Hall (1990) who found mark-ups to be procyclical. They also extend the analysis of mark-ups in US manufacturing by considering intermediate inputs and cyclical fluctuations of price margins. Their mark-up estimates are positive, but more moderate than earlier studies. They suggest that this is due to their consideration of intermediate inputs.

An analysis of mark-ups in a developing country is provided by Yalcin

${ }^{5}$ Nield (1963) and Rushdy and Lund (1967) 
(2000). He investigates the effect of increased import penetration on the price-cost margins of Turkish manufacturing firms in both the public and private sector. He finds that while import penetration leads to a decrease in the mark-up for the private sector as a whole, the mark-up in highly concentrated private sector industries increases with import penetration. Unlike the private sector, openness in industries associated with the public sector is found to decrease the mark-up.

For South Africa, two previous papers have examined the magnitude of price mark-ups over the marginal cost of production for South Africa. Fedderke et al (2006) find a significant mark-up in the South African manufacturing sector over the period 1970 to 1997, which in comparative terms is approximately twice that found for the US manufacturing sector. They also provide several alternative estimates of the mark-up that take into account a number of characteristics of the manufacturing sector's component industries, looking at both within-industry and between-industry effects. They find that the mark-up increases with both industry concentration and an industry's competitiveness relative to other industries. Furthermore, the mark-up is found to be lowered by import and export penetration and to be countercyclical in relation to the business cycle. They also note that including the price of intermediate inputs in the mark-up estimation reduces the extent of the mark-up. ${ }^{6}$

Edwards and Van De Winkel (2005) look at the mark-up over time and find that average mark-ups are in most cases lower in the 1980 s than in the 1970 s, but are significantly higher in the early 1990s. They suggest that this increase is due to high import surcharges imposed during this period; evidence consistent with the belief that mark-ups rise under protection. During the period of liberalization from 1994-2002, however, they find that mark-ups tend to decline or remain constant. Sensitivity of the mark-up to intermediate inputs is confirmed in their finding that average mark-ups in manufacturing fall from $42 \%$ to $12.5 \%$ with the inclusion of intermediate inputs. They also compare mark-ups in South African manufacturing to marks-ups obtained in studies on a range of foreign economies.? Although they find that mark-ups

\footnotetext{
${ }^{6}$ Including the price of intermediate inputs in the mark-up estimation will have a direct effect on the estimated labour adjustment parameter. This is because the price of intermediate inputs affects the elasticity of substitution between capital and labour, which appears as a term in the equation used to estimate the labour flexibility coefficient. This is not considered in the analysis in this paper and is left for further research.

${ }^{7}$ This is done with appropriate caution considering that other studies have employed
} 
in South Africa are generally comparable with mark-ups estimated in international studies, they find that the comparison is largely dependent on the inclusion or exclusion of intermediate inputs; when intermediate inputs are excluded, mark-ups in South Africa are high relative to the US while when intermediate inputs are included, mark-ups in South Africa appear relatively low.

Their study is limited by their use of a static fixed effects model. It has no dynamics (i.e. assumes a permanent steady-state) and does not account for heterogeneity across sectors. This may lead to bias and inconsistency. As with this study, the post-1996 volatility in the data is not accounted for.

This paper also makes a contribution to the debate surrounding labour flexibility and adjustment in South Africa. ${ }^{8}$ This is a topic that has received considerable attention in the South African literature. Much of the debate has centred on wage formation, wage flexibility and the wage elasticity of employment. Fedderke and Mariotti (2002) find that real wages are likely to be important in determining employment trends in the labour markets of the South African manufacturing sector. They find that where the growth rate in labour remuneration has been greater than the growth rate in labour productivity, there has been a tendency for employed labour to decline. However, their analysis is limited by only considering partial adjustments in labour.

Fields et al (2000) find that wage elasticities in the private formal sector in South Africa are substantial and growing, as well as varying strongly across sectors. Their results are weakened by estimation problems arising from the employed time series techniques. Fedderke et al (2000) provide the highest and most robust estimate of wage elasticity. ${ }^{9}$ They use a more fully-specified labour equation than earlier papers and test the sensitivity of their finding by utilizing a range of different specifications. Kingdon and Knight (2005) look at the flexibility of wages in response to local unemployment in South Africa. They find that the elasticity of wages to local unemployment rates in South Africa is similar to that found in other countries like the UK and US, but that this responsiveness is generally very low.

The evidence on labour market flexibility in South Africa is noted to be conflicting by Burger and Woolard (2005). They review contradictory find-

\footnotetext{
different empirical methodologies, time periods, data aggregation and data measurement.

${ }^{8}$ See Bhorat and Oosthuizen (2005) for a detailed analysis of the post-apartheid South African labour market.

${ }^{9}$ Their estimate is approximately 1.97 when they compute the wage elasticity using the ratio of user cost of capital to real wages.
} 
ings in the literature. These include a survey by the Economist Intelligence Unit that ranked South Africa last out of 60 countries in the labour flexibility afforded by its labour laws, as well as a contrasting World Bank study that ranked the South African labour market as the 16th most flexible out of the 133 countries included in the survey.

Our paper contributes to the debate on labour market flexibility by providing numerical estimates of the proportion of total labour in South African manufacturing that is devoted to fixed costs and as a result cannot respond to changing market conditions. ${ }^{10}$

\section{The Econometric Methodology}

We proceed with an estimation of equation (6) and equation (17). Since data employed for this study is stationary, estimation can proceed either by OLS or by Autoregressive Distributed Lag (ARDL) estimation.

\subsection{The Panel Estimator}

The panel estimator is provided by the Pooled Mean Group Estimator (PMGE) of Pesaran et al (1999). ${ }^{11}$

Consider the following model in which $i=1,2, \ldots, N$ and $t=1,2, \ldots, T$ denote the cross section units and time periods respectively:

Let $y$ be a scalar dependent variable and $\mathbf{x}(k \times 1)$ a vector of (weakly exogenous) regressors in the unrestricted error correction $\operatorname{ARDL}(p, q)$ representation:

$$
\begin{aligned}
\Delta y_{i t}= & \phi_{i} y_{i, t-1}+\beta_{i}^{\prime} x_{i, t-1}+\sum_{j=1}^{p-1} \lambda_{i j} \Delta y_{i, t-j}+\sum_{j=0}^{q-1} \delta_{i j}^{\prime} \Delta x_{i, t-j} \\
& +\mu_{i}+\varepsilon_{i t}, \forall i, t
\end{aligned}
$$

Fixed effects for each group $i$ are captured by the $\mu_{i}$ terms. The error terms $\varepsilon_{i t}$ are independently distributed across space $(i)$ and time $(t)$ with zero means and constant group-specific variances denoted by $\sigma_{i}^{2}>0$. If we assume that

${ }^{10}$ Note that this paper does not address the cause of rigidities or flexibilities in the South African labour market. Although possible explanations are suggested, it is beyond the scope of this paper to scrutinize any of these claims.

${ }^{11}$ See also the discussion in Fedderke et al (2000) and Fedderke (2004). 
$\phi_{i}<0$ for all $i$, then there exists a long-run relationship between $y_{i t}$ and $\mathbf{x}_{i t}$ given by:

$$
y_{i t}=\boldsymbol{\theta}_{i}^{\prime} \mathbf{x}_{i t}+\eta_{i \ell}, \forall i, t
$$

where $\boldsymbol{\theta}_{i}=-\boldsymbol{\beta}_{i}^{\prime} / \phi_{i}$ is the $k \times 1$ vector of the long-run coefficients. The $\eta_{i t}$ terms are stationary with possibly non-zero means (including fixed effects). Substitution then allows equation (18) to be written as:

$$
\Delta y_{i t}=\phi_{i} \eta_{i, t-1}+\sum_{j=1}^{p-1} \lambda_{i j} \Delta y_{i, t-j}+\sum_{j=0}^{q-1} \delta_{i j}^{\prime} \Delta x_{i, t-j}+\mu_{i}+\varepsilon_{i t}, \forall i, t
$$

where $\eta_{i, t-1}$ is the error correction term given by equation (19). We can now interpret $\phi_{i}$ as the error correction coefficient measuring the speed of adjustment towards the long-run equilibrium for each group $i$.

This is the general framework from which we formulate the PMGE. We allow the intercepts, short-run coefficients and error variances to differ freely across groups, but require the long-run coefficients to be homogenous; i.e. $\boldsymbol{\theta}_{i}=\boldsymbol{\theta} \forall i$. Group-specific short-run coefficients and the common longrun coefficients are computed by pooled maximum likelihood estimation. Denoting these group-specific estimators by $\tilde{\phi}_{i}, \tilde{\boldsymbol{\beta}}_{i}, \tilde{\lambda}_{i j}, \tilde{\boldsymbol{\delta}}_{i j}$ and $\tilde{\boldsymbol{\theta}}$, we obtain the PMG estimators by taking arithmetic means; i.e. $\hat{\phi}_{P M G}=\frac{\sum_{i=1}^{N} \tilde{\phi}_{i}}{N}$, $\hat{\boldsymbol{\beta}}_{P M G}=\frac{\sum_{i=1}^{N} \tilde{\beta}_{i}}{N}, \hat{\lambda}_{j P M G}=\frac{\sum_{i=1}^{N} \tilde{\lambda}_{i j}}{N}, j=1, \ldots, p-1$, and $\hat{\boldsymbol{\delta}}_{j P M G}=\frac{\sum_{i=1}^{N} \tilde{\delta}_{i j}}{N}, j=$ $0, \ldots q-1, \hat{\boldsymbol{\theta}}_{P M G}=\tilde{\boldsymbol{\theta}}$.

Fedderke et al (2006) note that PMGE provides an intermediate case between the dynamic fixed effects (DFE) estimator which imposes the homogeneity assumption for all parameters except for the fixed effects, and the mean group estimator (MGE) proposed by Pesaran and Smith (1995), which allows for heterogeneity of all parameters. Although it admits short-run heterogeneity, PMGE exploits the statistical power offered by the panel through long-run homogeneity.

Pesaran and Smith (1995) draw attention to the threat of inefficiency and inconsistency associated with an unjustified assumption of long-run homogeneity. In order to test the validity of assuming long-run homogeneity, a Hausman (1978) test (hereafter $h$ test) on the difference between the MG and PMG estimates of long-run coefficients is employed. Note that only the PMG estimation results are reported if the Hausman test allows us to accept the inference of homogeneity across sectors. 
The advantage of the PMG estimator is that is recognizes the presence of a long-run equilibrium relationship and explicitly models the dynamics of adjustment towards this equilibrium at the same time. It is appropriate in an analysis of the mark-up of prices over marginal cost as it is consistent with the theory of homogeneity in the mark-up in the long run and the possible heterogeneity of mark-up dynamics in the short-run. Fedderke et al (2006) confirm preference for the use of PMGE in the context of estimating mark-ups and note that as long as sector-homogeneity is assured, the PMGE offers efficiency gains over the MGE while granting the possibility of dynamic heterogeneity across sectors unlike the DFE estimator. ${ }^{12}$

\subsection{The ARDL Approach to Cointegration ${ }^{13}$}

Hsiao (1997) lays the foundations for the use of conventional estimation techniques where the forcing variables are strictly exogenous, regardless of whether the variables are $I(0)$ or $I(1)$. Hsiao demonstrates that where forcing variables are strictly exogenous, conventional Wald statistics are asymptotically distributed (under the null of reduced rank cointegration). This allows for the restriction of the parameter space at the most general stage, economizing on degrees of freedom. Pesaran and Shin (1995) advocate the use of autoregressive distributed lag models for the estimation of long run relations, suggesting that once the order of the ARDL has been established, estimation and identification can proceed by OLS. While the presence of a long run relationship between variables remains critical to valid estimation and inference. Pesaran and Shin (1995) demonstrate that valid asymptotic inferences on short- and long-run parameters can be made under least squares estimates of an ARDL model, provided the order of the ARDL model is appropriately augmented to allow for contemporaneous correlations between the stochastic components of the data generating processes included in estimation. Hence ARDL estimation is applicable even where the explanatory variables are endogenous. Additionally ARDL remains valid irrespective of the order of integration of the explanatory variables. The ARDL methodology thus has the advantage of not requiring a precise identification of the order of integration of the underlying data.

\footnotetext{
${ }^{12}$ Yongcheol Shin is thanked for the provision of the appropriate GAUSS code for estimation purposes.

${ }^{13}$ This section is largely taken from Fedderke et al (2006).
} 

by:

The PSS approach begins by estimating the error correction model given

$$
\Delta y_{t}=\alpha_{0}+\sum_{i=1}^{p} \beta_{i} \Delta y_{t-i}+\sum_{j=1}^{k} \sum_{i=1}^{p} \gamma_{j i} \Delta x_{j, t-i}+\left(\delta_{1} y_{t-1}+\sum_{j=1}^{k} \delta_{j+1} x_{t-j}\right)+\varepsilon_{t}(21)
$$

and estimating by means of an F-test (henceforth referred to as PSS F-tests) the significance of a joint zero restriction on the $\delta^{\prime} s$ of the error correction model. The distribution of the F-test is non-standard, and critical values are provided by Pesaran et al (1996). The test is further subject to potential ambiguity, in the sense that the test has an upper and lower critical bound value. As long as the computed statistic exceeds the upper bound, the null of no association can be unambiguously rejected. Similarly, as long as the computed statistic falls below the lower bound, the null of no association cannot be rejected. However, where the test statistic falls between the upper and lower bounds, it is indeterminate.

The need to establish the existence of a unique long run relationship (i.e. that the F-tests confirm only one of the variables included in estimation as an outcome variable and that all other variables act as forcing variables) and the selection of an appropriate order to the ARDL remain critical. We follow Pesaran and Shin (1995) in a two step strategy, selecting the ARDL orders on the basis of the Akaike Information criterion (AIC), then estimating the long and short run coefficients on the basis of the selected model. Estimation can be shown to be feasible on the basis of the "Bewley regression":

$$
y_{t}=\zeta+\eta t+\sum_{i=1}^{k} \theta_{i} x_{i}+\sum_{j=0}^{p-1} \gamma_{j} \Delta y_{t-j}+\sum_{m=0}^{q-1} \delta_{m} \Delta x_{t-m}
$$

by the instrumental variables method, where $1, t, \sum_{i=1}^{k} x_{i}, \sum_{j=0}^{p-1} \Delta y_{t-j}$, $\sum_{m=0}^{q-1} \Delta x_{t-m}$, serve as instruments. ${ }^{14}$

The methodology has the advantage of providing a means of testing for the patterns of association between the variables employed for the present study (by means of the PSS F-tests). We do not exploit this in this analysis.

\footnotetext{
${ }^{14}$ The methodology outlined presumes that the $x_{i}$ and $\epsilon$ are uncorrelated. When they are correlated, the methodology remains valid, but the "Bewley regression" requires angmentation.
} 


\section{Results}

\subsection{Data}

The data employed for this study focus on the three digit manufacturing industries, over the 1970-2004 period. Variables for the manufacturing sector include the output, capital stock, and labour force variables and their associated growth rates. Data are obtained from the Trade and Industrial Strategies (TIPS) database. We employ both panel data and individual industry data for the purposes of estimation, with observations from 1970 through 2004. The panel employs data for the 28 three-digit SIC version 5 manufacturing industries in the South African economy for which data is available. Due to problems with data availability some sectors are omitted for parts of the analysis. These omissions are discussed with the results.

There are questions over the reliability of industry data post-1996. Since the last manufacturing survey was undertaken by Statistics South Africa in 1996, data post-1996 have been disaggregated from the 2-digit sector level on the basis of input-output tables. ${ }^{15}$ The large sample manufacturing survey of 2001 does not appear to have been incorporated into the data, and moreover the 2001 survey has not released the labour component of the survey. The reliability of the data has suffered as a result of this data collection strategy.

This is evident from the evidence presented in Table 1C, which reports standard deviations of the computed mark-ups for this study. We report only the standard deviations for computed mark-ups, since this measure summarizes the output, capital and labour dimensions in the manufacturing sector. Standard deviations increase substantially post- 1996 for all sectors, and increase even more markedly after 2000 . Several sectors show strong spikes in the standard deviations either for both of the last two sub-periods or for the last sub-period (1991-2000 and 1995-2004). In the instance of some sectors (e.g.. Rubber products), the increase is of very substantial magnitude. This reflects increased underlying volatility in the component data from which the mark-ups are computed, although it is worth emphasizing that this volatility is less visible in the component data. (Results to show this are available on request, but are not reported due to space constraints.)

In interpreting the results that follow, the caveat that the reliability of all

\footnotetext{
${ }^{15}$ The TIPS database cites a 1998 Statistics South Africa input-output table as the most recent input-output table used as a primary data source in the compilation of the database.
} 
results based on industry data are likely to decline substantially after 1996 must be borne in mind. There is no adequate means of compensating for the absence of data collection for the manufacturing sector, and after having collected manufacturing censuses on a biennial basis since 1917, South Africa simply ceased doing so in 1996.

\subsection{Roeger Results}

We have taken two approaches to investigate the mark-up: a computational approach and an estimation approach.

The computational approach involves re-arranging equation (6) so that the mark-up is expressed in terms of the growth rates of real value-added, labour inputs and capital inputs in the following way:

$$
\begin{aligned}
\mu-1 & =\frac{N S R}{\alpha[\Delta(w+l)-\Delta(r+h)]} \\
& =\frac{\Delta(p+q)-\alpha \Delta(u+l)-(1-\alpha) \Delta(r+k)}{\alpha[\Delta(u+l)-\Delta(r+k)]}
\end{aligned}
$$

The mark-up is then computed for each year using annual values of these variables.

As we are interested in the trend of the mark-up over time, we split the full sample period into several overlapping ten-year sub-periods and calculate the average computed mark-up for each sub-period to allow for investigation of the trend over time. The results are reported in Table 1A.

Since cyclical variability and measurement error generate volatility in the results, we also present the results of the computation after having filtered by means of Hodrick-Prescott in Table 1B. The Hodrick-Prescott filter represents a smoothing of a time series such that the smoothed time series, denoted $y^{*}$, is obtained from:

$$
y^{*}=\min _{y_{1}^{*} \ldots y_{n}^{*}}\left\{\sum_{t=1}^{n}\left(y_{t}-y_{t}^{*}\right)^{2}+\lambda \sum_{t=1}^{n-1}\left(\Delta^{2} y_{t+1}^{2}\right)\right\}
$$

where $\lambda$ denotes a smoothing parameter. For annual data the conventional smoothing parameter is set at 7 . Given the volatility of the computed markup we set the smoothing parameter considerably more aggressively at 1000 .

In order to show the volatility of the computed mark-up over time, the standard deviation of the mark-up for each sub-period is also reported (Table $1 \mathrm{C})$. 
The resultant trend structure in the mark-up implied from the direct computations is generally symmetrical to the estimated values reported below, although the absolute values of the implied mark-ups continue to reflect the underlying volatility of the series. This is evident even for the smoothed series despite the aggressive application of the Hodrick-Prescott filter. This trend is an initial fall in the mark-up (from a moderate base) which is followed by a rise in the mark-up from the mid-1990s. A good example is provided by the Food sector. We see an initial mark-up of $70 \%$ in the 1971-80 sub-period, lower mark-ups in the next two sub-periods, and substantial increases in the mark-up over the next three sub-periods (with a mark-up approaching $200 \%$ in the 1995-2004 sub-period). ${ }^{16}$

Estimation is preferred to computation due to its more reliable results. The estimation approach involves using the specification:

$$
\begin{aligned}
N S R_{i t} & =\gamma_{0 i}+\gamma_{1} R O E G E R_{i t}+\varepsilon_{i t} \\
\text { where ROEGER } & \left.=\alpha_{i t} \mid \Delta(w+l)_{i t}-\Delta(r+k)_{i t}\right]
\end{aligned}
$$

In Table 2 we report the average manufacturing sector mark-up, both over the full sample period, as well as rolling decade-long sub-periods, estimated from the panel data set. Results indicate the presence of an aggregate markup for the manufacturing sector over the full sample period of $54 \%$. The errorcorrection term, the $\phi$-parameter, indicates that adjustment to the long-run equilibrium is rapid as it is close to unity. The Hausman test accepts the inference of an homogenous mark-up across sectors for the long run.

The declining trend in the aggregate manufacturing sector mark-up noted by Edwards and Van De Winkel (2005) is again evident in the estimates. However, the decline in the mark-up is evident prior to the period of liberalization of the economy (proving lowest during the period of maximal closure of the economy (1975-90)), while post-liberalization the trend in the mark-up reverses and it increases. (The estimated mark-up is 50\% in the 1991-2000 sub-period and rises to $62 \%$ in the 1995-2004 sub-period.) This is supportive of the hypothesis that the mark-up is procyclical as the fall in the markup and its subsequent rise post-1994 mirrors the general performance of the South African economy over the same period. However, this result needs to be treated cautiously as it contradicts the finding of Fedderke et al (2006) in

\footnotetext{
${ }^{16}$ Recall that the data post-1996 has been disaggregated by algorithm. Spikes in the computed mark-ups may be caused by imposing similar nominal wage and rental growth rates that results in the denominator of equation (23) tending to zero.
} 
which mark-ups were found to be countercyclical. Their econometric model explicitly captures the short-run cyclical dynamics of the mark-up while our procyclical observation is based only on the long-run. This suggests that there may be a divergence in how the mark-up relates to the business cycle over the short-run and the long-run.

Fedderke et al (2006) and Edwards and Van De Winkel (2005) suggest that trade liberalization should lower the mark-up. It is argued that South Africa liberalized in the 1990s. However, our results associate this period with an increase in the mark-up rather than a decrease. There are three possible reasons for this. First, in an analysis of effective rates of protection, Fedderke and Vaze (2001) conclude that liberalization was incomplete, although there are dissenting voices on this (Rangasamy and Harmse (2003) and Edwards (2005)). ${ }^{17}$ Second, the substantial depreciation of the rand/dollar exchange rate over this period may have neutralized the effects of liberalization. And, third, liberalization may have had effects on the composition of industry as inefficient firms shut down, leaving only efficient firms with high price-cost margins.

We note here that at the sectoral level the regressors are almost without exception stationary. (The only exception being Basic Iron and Steel.) This is shown in Table 3. ARDL is thus an appropriate estimation strategy (with efficiency gains over OLS in the presence of dynamics). Also note that due to the small sample size of the data at the individual sector level, our sectoral results have low statistical power. These sectoral results are therefore less reliable than the results for the manufacturing sector as a whole. As a result, the behaviour of the estimated mark-up for some individual sectors may be inconsistent with the behaviour of the mark-up for the manufacturing sector as a whole.

In Table 4 we report the three digit manufacturing sector mark-up estimates obtained from the PSS ARDL cointegration estimations. Again, estimated mark-ups are both for the full sample period, as well as for rolling decade-long sub-periods. The mark-up estimates for the full sample period estimation generally fall in a plausible range; the majority of them lying between $10 \%$ and $100 \%$. We also find general consistency with the computation results. (Note, for example, that the sub-period estimates for the Food sector are similar to the computation results discussed above; we have an initial mark-up of $79 \%$ that falls to $61 \%$ in the 1980 s but rises to over $100 \%$ in the

\footnotetext{
${ }^{17}$ See the response by Fedderke and Vaze (2004), as well as Holden (2005).
} 
1995-2004 sub-period.)

The mark-up is consistently statistically significant across all 3-digit manufacturing sectors. There is also variation across sectors in the size of the mark-up. This is despite the finding reported in Table 2 of cross-sector homogeneity in the panel estimations. Sub-period estimations indicate a range of differential responses in the size of mark-up across sectors. For several sectors, there seems to be an increase in the mark-up in the last sub-period or in the last few sub-periods. However, there are also some sectors in which the estimated mark-up decreases. In Table 5 we summarize by placing sectors into six main categories: high mark-ups that either decline, rise or stay the same into the last within-sample decade (1995-2004); or low mark-ups that either decline, rise or stay the same into the last within-sample decade (1995-2004).

Note that when looking at the estimations for individual sectors over the full sample period, it is clear that for Tobacco, Coke \& Refined Petroleum and Other Manufacturing the estimated mark-up is implausibly high (all have mark-ups in excess of $200 \%$ ), suggesting that there may be problems with the estimation or data. Historically, the data associated with these sectors are typically problematic. ${ }^{18}$

The standard errors and diagnostics for the full sample period estimation are reported in Table 6 . This establishes the presence of a statistically sound estimated mark-up for each of the manufacturing sectors other than Glass and Glass Products. For this sector, consistent serial correlation in the error terms results in biased and inconsistent point estimates of the standard errors. We therefore do not report an estimate of the mark-up for this sector.

Given the small sample size of the sub-period estimations, we do not report standard errors and diagnostics for these estimations.

\subsection{Labour Adjustment Results}

In order to econometrically investigate the relationship between the mark-up and labour adjustment, equation (17) suggests a specification of the form:

$$
\begin{aligned}
y_{i t} & =\beta_{0 i}+\beta_{1} \Delta k_{i t}+\beta_{2} \Delta l_{i t}+\varepsilon_{i t} \\
\text { where } y_{i t} & =\frac{1}{1-\alpha_{i t}}\left(\frac{\Delta \log \mu_{i t}-\left((\Delta q+\Delta p)_{i t}-\Delta w_{i t}\right)}{\overline{\mu_{i}}}-\alpha_{i t} \Delta l_{i t}\right)
\end{aligned}
$$

${ }^{18}$ See the discussion in various papers such as Fedderke et al (2000) and Fedderke et al (2006). 
with the expressions represented by $\beta_{1}$ and $\beta_{2}$ following directly from (17).

Two of the required variables are not available directly from the original panel data set: the steady-state mark-up $(\bar{\mu})$ and the growth rate of the markup $(\Delta \log \mu)$. We use the mark-up that was estimated over the full sample period from the previous section as the steady-state mark-up for each sector and use the smoothed computed mark-up series to calculate the growth rate of the mark-up for each sector. We justify using the computed mark-up series despite its volatility as we have found that the results are not sensitive to the growth rate of the mark-up. ${ }^{19}$

A simple manipulation of the estimated coefficients $\beta_{1}$ and $\beta_{2}$ (considering the expressions they represent from equation (17)) allows us to obtain an estimate of the labour adjustment coefficient, $\frac{L}{L-\bar{L}}$. We use $\beta_{1}$ to obtain an estimate of the elasticity of substitution between capital and labour as in equation (27). Then we use $\beta_{2}$ along with the estimate of the elasticity of substitution to obtain an estimate of the labour adjustment coefficient as in equation (28).

$$
\begin{aligned}
& \beta_{1}=\left(\frac{1}{\sigma}-1\right) \Rightarrow \sigma_{c s t}=\frac{1}{\beta_{1}+1} \\
& \beta_{2}=\frac{1}{\sigma} \frac{L}{L-\bar{L}} \Rightarrow \frac{L}{L-\bar{L}}=\sigma \beta_{2}=\frac{\beta_{2}}{\beta_{1}+1}
\end{aligned}
$$

Under circumstances in which $\beta_{1}$ is not significantly different from zero, we assume an elasticity of substitution of unity in the calculation of the labour adjustment coefficient. This follows directly from $\beta_{1}=0$. Note that when we calculate the labour adjustment coefficient, the "correct" elasticity of substitution is defined to be $\sigma_{e s t}$ as in (27) if $\beta_{1}$ is significantly different from zero and unity if it is not significantly different from zero. As a result, when we consider a unitary elasticity of substitution, $\frac{L}{L-\bar{L}}=\beta_{2}$ and not the expression in equation (28).

We report the PMGE results for the manufacturing sector in Table 7. Results indicate the presence of an aggregate labour adjustment coefficient for the manufacturing sector over the full sample period of between 2.84 and 3.43 , depending on which lag structure is adopted. This would suggest that

\footnotetext{
${ }^{19}$ For example, imposing a growth rate of zero on the mark-up rather than calculating the growth rate from the computed mark-up series did not have a considerable impact on the estimation results.
} 
of the total labour employed in manufacturing in South Africa, two-thirds is devoted to fixed costs and one-third is devoted to variable costs. ${ }^{20}$

The error-correction term, the $\phi$-parameter, indicates that adjustment to the long-run equilibrium is rapid. The speed of adjustment is also increasing with increases in the adopted lag structure. The Hausman test accepts the inference of an homogenous labour adjustment coefficient across sectors for the long run, justifying the use of the PMG estimator.

In order to investigate the trend of the labour adjustment coefficient over time, we use a similar approach to the sub-period approach used in the previous section. We run the estimation on fifteen-year sub-periods and roll these through the full sample period year-by-year. The results are reported in Table 8, as well as shown in Figures 1A and 1B. The general pattern that, emerges is a $U$-shape: a decreasing labour adjustment coefficient through the first half of the sample followed by an increasing labour adjustment coefficient in the second half of the sample. Note that a decreasing coefficient is associated with an increase in labour flexibility.

We also include a plot in which third degree polynomial trendlines have been added. The U-shape is evident in three of the trendlines; the only exception being the model with an optimal lag structure chosen by an Akaike Information Criterion allowing two lags and enforcing a unitary elasticity of substitution. It can be seen that use of the "correct" sigma exaggerates the fall and subsequent rise of the labour adjustment coefficient, while forcing sigma to be unity generally results in a greater labour adjustment coefficient. Trends associated with the use of the "correct" sigma reveal that the labour adjustment coefficient falls by about one third (from an initial level of four to around two and a half in the 1978-92 sub-period) before rising towards the original level in the latter sub-periods. This is followed by a tapering of the coefficient in the last one or two sub-periods.

Although it is beyond the scope of this paper, we suggest possible interpretations of this behaviour. First, we note that labour flexibility over the 1980s may be different because this is the period in which the closure of the South African economy was greatest. Second, the response to the upward real wage pressure associated with the unionization of the 1980s may have been an enforced increased flexibility in labour hours. Third, the growth

\footnotetext{
${ }^{20}$ It would be useful to contextualize this through comparisons with other countries, but we are not aware of literature on this. Oliviera Martins and Scarpetta (1999) considered cases where the fixed amount of labour represented either $20 \%$ or $40 \%$ of total labour inputs.
} 
in the manufacturing sector over the 1990s may have been associated with increased wages rather increases in the number of employed workers.

There are a variety of explanations as to why the manufacturing growth of the 1990s did not translate into growth in the number of employed workers. One possibility is that the labour legislation introduced in the second half of the $1990 \mathrm{~s}^{21}$ allowed for flexibility in wages, but decreased flexibility in the number of workers employed. This is suggested by an IMF country report (2005) that identifies the labour laws associated with hiring and dismissal as being particularly responsible for inflexibilities in the South African labour market rather than other factors.

In Table 9 we compare the labour adjustment coefficient across sectors. These are estimates over the full sample period obtained from the PSS ARDL cointegration estimations. For some of the sectors it was necessary to use time dummies to control for outliers and ensure sound diagnostics. ${ }^{22}$ There are also some sectors in which statistically sound results were not obtained. (Results for these sectors are omitted.) Although both the labour adjustment coefficient with $\sigma=\sigma_{e s t}$ and the labour adjustment coefficient with $\sigma=1$ are reported, it is the column associated with the "correct" $\sigma$ in which we are interested. It is the labour adjustment coefficient in this column that is used to provide the summary table, Table 10 . This is a table that characterizes each sector as either one that has high rigidity in labour adjustment (large degree of labour is devoted to fixed costs), medium rigidity in labour adjustment or low rigidity in labour adjustment. Not surprisingly, some of the highly unionized sectors (such as Textiles and Motor Vehicles, Parts and Accessories) are in the most rigid category, while some of the sectors in which labour is not a significant cost are in the least rigid category (such as Basic Iron and Steel).

We also look at the trend of the sector-specific labour adjustment coefficient over time. Results are reported in Table $11 .^{23}$ We do not draw strong conclusions from these results as we recall that sectoral results have low statistical power due to the small sample size.

Note that in order to obtain sensible results, it was necessary to either choose a constant elasticity of unity throughout all the sub-periods or use

${ }^{21}$ These include the Labour Relations Act of 1996, the Basic Conditions of Employment Act of 1997 and the Employment Equity Act of 1998.

${ }^{22}$ See appendix for details.

${ }^{23}$ Note that there are several omitted values and sectors. These indicate circumstances in which statistically reliable results were not obtained. 
the variable elasticity of substitution throughout all the sub-periods when obtaining the labour adjustment coefficient. This is because if we change from using an elasticity of unity in one sub-period to the variable elasticity of substitution in the following sub-period, changes in the labour adjustment coefficient are potentially due to the change in the elasticity of substitution rather than the behaviour of the labour market. We chose unitary or variable elasticities for each sector based on the general trend in the significance of the $\beta_{1}$ in the sub-period estimations, and for only two sectors chose to use variable elasticities: Basic Chemicals and Basic Iron and Steel.

\section{Conclusion}

We find evidence of imperfect competition and pricing power in South African manufacturing through the presence of an aggregate mark-up of around $50 \%$ for the sector over the period from 1970 to 2004. When looking at the trend of the mark-up over time, our results suggest that the mark-up fell from a moderate base during the 1970s and 1980s before rising again after the liberalization of the South African economy in the early 1990s. This is supportive of the hypothesis that the mark-up is procyclical as the markup mirrors the general performance of the South African economy over the same period. As discussed, this finding is in contrast to the countercyclical mark-ups obtained by Fedderke et al (2006).

The analysis of individual sectors reveals strong variation in the magnitudes and trends of mark-ups at the sectoral level. This is indicative of their different characteristics and responses to economic stimuli.

Labour market flexibility (particularly the ease of labour adjustment) is investigated through an extension of the mark-up analysis. It is found that of the total labour employed in manufacturing in South Africa, two-thirds is devoted to fixed costs and one-third is devoted to variable costs. We also look at the trend of this proportion over time. Results indicate that there is an increase in labour flexibility in the 1970s and early 1980s (a higher proportion of labour is devoted to variable costs) followed by a decrease in labour flexibility in the 1990s.

The decrease in flexibility in the 1990 s presents a concern to policy-makers if it is assumed that rigid labour markets impede employment growth. It suggests that policies to promote labour flexibility deserve consideration if 
employment growth is the primary policy objective. ${ }^{24}$

Again, results at the sectoral level reveal considerable differences in the characteristics of labour markets across sectors.

${ }^{24}$ The nature of these policies needs to be based on more detailed research into the causes of rigidities in the South African labour market. 


\section{References}

Basu, S., 1995, Intermediate Goods and Business Cycles: Implications for Productivity and Welfare, American Economic Review, 85, 512-31

Bhorat, H. and M. Oosthuizen, 2005, The Post-Apartheid South African Labour Market, Development Policy Research Unit Working Paper 05/93

Burger, R. and I. Woolard, 2005, The State of the Labour Market in South Africa After the First Decade of Democracy, Centre for Social Science Research Working Paper No. 133

Edwards, L., 2001, Globalization and the Occupational Structure of Employment in South Africa, South African Journal of Economics, 69 (1)

Edwards, L., 2005, Has South Africa Liberalized its Trade?, South African Journal of Economics, 73 (4), 754-75

Edwards, L. and T. van de Winkel, 2005, The Market Disciplining Effects of Trade Liberalization and Regional Import Penetration on Manufacturing in South Africa, Trade and Industrial Policy Strategies Working Paper 1/2005

Fallon, P. and R. Lucas, 1998, South Africa: Labor Markets, Adjustment and Inequalities, Discussion Paper No. 12, Southern Africa Department, World Bank, Washington D. C.

Fedderke, J. W., 2004, Investment in Fixed Capital Stock: Testing for the Impact of Sectoral and Systematic Uncertainty, Oxford Bulletin of Economics and Statistics, 66 (2), 165-87

Fedderke, J. W., Kularatne, C. and M. Mariotti, 2006, Mark-up Pricing in South African Industry, Journal of African Economies (forthcoming)

Fedderke, J. W. and M. Mariotti, 2002, Changing Labour Market Conditions in South Africa. A Sectoral Analysis of the Period 1970-1997, South African Journal of Economics, 70 (5), 830 
Fedderke, J. W., Shin, Y. and P. Vaze, 2000, Trade and Labour Usage: An Examination of the South African Manufacturing Industry, Econometric Research Southern Africa Working Paper No. 15, University of the Witwatersrand

Fedderke, J. W. and P. Vaze, 2001, The Nature of South Africa's Trade Patterns, South African Journal of Economics, 69 (3), 436-73

Fedderke, J. W. and P. Vaze, 2004, Response to Rangasamy and Harmse: Trade Liberalization in the 1990s, South African Journal of Economics, 72 (2), 408-13

Fields, G., Leibbrandt, M. and J. Wakeford, 2000, Key Labour Market Elasticities, Report Prepared for the Department of Finance of the South African Government

Hakura, D. S., 1998, The Effects of European Economic Integration on the Profitability of Industry, International Monetary Fund Working Paper WP $/ 98 / 85$

Hall, R. E., 1990, The Invariance Properties of Solow's Productivity Residual, in P. Diamond (Ed..) Growth, Productivity, Unemployment (MIT Press, Cambridge MA)

Hall, R. L. and C. J. Hitch, 1939, Price Theory and Business Behaviour, Oxford Economic Papers, 2

Hausman, J., 1978, Specification Tests in Econometrics, Econometrica, 46, 1251-71

Holden, M., 2005, Trade Liberalization in South Africa Once Again, South African Journal of Economics, 73 (4), 776-84

Hsiao, C., 1997, Cointegration and Dynamic Simultaneous Equations Model, Econometrica, 65, 647-70

IMF Country Report, 2005, South Africa: Selected Issues, IMF Coumtry Report No. 05/345

Kingdon, G. and J. Knight, 2005, How Flexible are Wages in Response to Local Unemployment in South Africa? Global Poverty Research Group Working Paper GPRG-WPS-015 
McCallum, B. T., 1970, The Effect of Demand on Prices in British Manufacturing: Another View, Review of Economic Studies, 37 (1), $147-56$

Nield, R. R., 1963, Pricing and Employment in the Trade Cycle (Cambridge)

Oliviera Martins, J. and S. Scarpetta, 1999, The Levels and Cyclical Behaviour of Mark-ups Across Countries and Market Structures, OECD Economics Department. Working Papers No. 213

Pesaran, M. H., Shin, Y. and R. Smith, 1996, Testing for the Existence of a Long-Run Relationship, DAE Working Paper, Department of Applied Economics, University of Cambridge, Amalgamated Series, No. 9622

Pesaran, M. H., Shin, Y. and R. Smith, 1999, Pooled Mean Group Estimation of Dynamic Heterogenous Panels, Journal of the American Statistical Association, 94, 621-34

Pesaran, M. H. and Y. Shin, 1995, An Autoregressive Distributed Lag Modelling Approach to Cointegration Analysis, Cambridge Working Papers in Economics 9514, Faculty of Economics (formerly DAE), University of Cambridge

Pesaran, M. H. and R. Smith, 1995, Estimating Long-Run Relationships from Dynamic Heterogenous Panels, Journal of Econometrics, $68,79-113$

Rangasamy, L. and C. Harmse, 2003, Revisiting the Extent of Trade Liberalization in. the 1990s, South African Journal of Economics, 70 (4), $705-728$

Roeger, W., 1995, Can Imperfect Competition Explain the Difference Between Primal and Dual Productivity Measures? Estimates for US Manufacturing, Journal of Political Economy, 103, 316-30

Rushdy, F. and P. J. Lund, 1967, The Effect of Demand on Prices in British Manufacturing, Revieu of Economic Studies. 34 
Uzawa, H., 1962, Production Functions with Constant Elasticities of Substitution, Review of Economic Studies, 29 (4), 291-9

Wittenberg, M., 2002, Job Search in South Africa: A Nonparametric Analysis, South African Journal of Economics, 70 (8), 1163

Yalcin, C., 2000, Price-Cost Margins and Trade Liberalization in Turkish Manufacturing Industry: A Panel Data Analysis, Mimeo: Turkiye Cumhuriet Merlez Bankasy AraPtyrma Genel Mudurluou 


\author{
Appendix A: \\ List of Manufacturing Sectors \\ Manufacturing 3-digit Sectors \\ Food \\ Beverages \\ Tobacco \\ Textiles \\ Wearing apparel \\ Leather \& leather products \\ Footwear \\ Wood \& wood products \\ Paper \& paper products \\ Printing, publishing \& recorded media \\ Coke \& refined petroleum \\ Basic chemicals \\ Other chemicals \& man-made fibers \\ Rubber products \\ Plastic products \\ Glass \& glass products \\ Non-metallic minerals \\ Basic iron \& steel \\ Basic non-ferrous metals \\ Metal products excluding machinery \\ Machinery \& equipment \\ Electrical machinery \& apparatus \\ Television, radio \& communication \\ equipment \\ Professional \& scientific equipment \\ Motor vehicles, parts \& accessories \\ Other transport equipment \\ Furniture \\ Other manufacturing
}

Time Dummies Controlling for Outliers in Individual Sector Analysis

\begin{tabular}{|c|c|c|c|c|c|c|c|c|}
\hline $\begin{array}{l}\text { Code } \\
\text { Food }\end{array}$ & \multicolumn{4}{|c|}{ Mark-up } & \multicolumn{4}{|c|}{ Labour Adjustment } \\
\hline Beve & $N$ & & & & $Y$ & 1982 & 1988 & \\
\hline Toba & $N$ & & & & $n / a$ & & & \\
\hline Text & Yes & 2002 & & & $Y$ & 1993 & & \\
\hline Wear & $Y$ & 1998 & 1999 & 2000 & $N$ & & & \\
\hline Leat & $Y$ & 1998 & 1999 & 2002 & $Y$ & 2003 & & \\
\hline Foot & $Y$ & 2000 & & & $N$ & & & \\
\hline Wood & $N$ & & & & $N$ & & & \\
\hline Pape & $N$ & & & & $n / a$ & & & \\
\hline Prin & $\mathrm{N}$ & & & & $N$ & & & \\
\hline Coke & $N$ & & & & $N$ & & & \\
\hline Chem & $N$ & & & & $N$ & & & \\
\hline Otch & $\gamma$ & 2000 & & & $n / a$ & & & \\
\hline Rubb & $Y$ & 1999 & & & $Y$ & 1987 & 1988 & \\
\hline Plas & $Y$ & 1998 & 2002 & & $Y$ & 1977 & 2000 & 2001 \\
\hline Glas & $Y$ & 1986 & 2001 & & $N$ & & & \\
\hline Nmet & $N$ & & & & $N$ & & & \\
\hline Iron & $Y$ & 2000 & 2002 & & $Y$ & 1999 & & \\
\hline Nfer & $N$ & & & & $\mathrm{n} / \mathrm{a}$ & & & \\
\hline Meta & $N$ & & & & $N$ & & & \\
\hline Mach & $Y$ & 1999 & & & $Y$ & 1999 & & \\
\hline Elec & $N$ & & & & Y & 1994 & & \\
\hline Tele & $Y$ & 1998 & 2002 & & $\mathrm{n} / \mathrm{a}$ & & & \\
\hline Prof & $Y$ & 1998 & 2002 & & $N$ & & & \\
\hline Moto & $N$ & & & & $Y$ & 1998 & & \\
\hline Ottr & $Y$ & 1997 & & & $\mathrm{n} / \mathrm{a}$ & & & \\
\hline Furn & $Y$ & 1998 & & & $Y$ & 1977 & 1978 & 1998 \\
\hline Otma & $N$ & & & & $\mathrm{n} / \mathrm{a}$ & & & \\
\hline
\end{tabular}




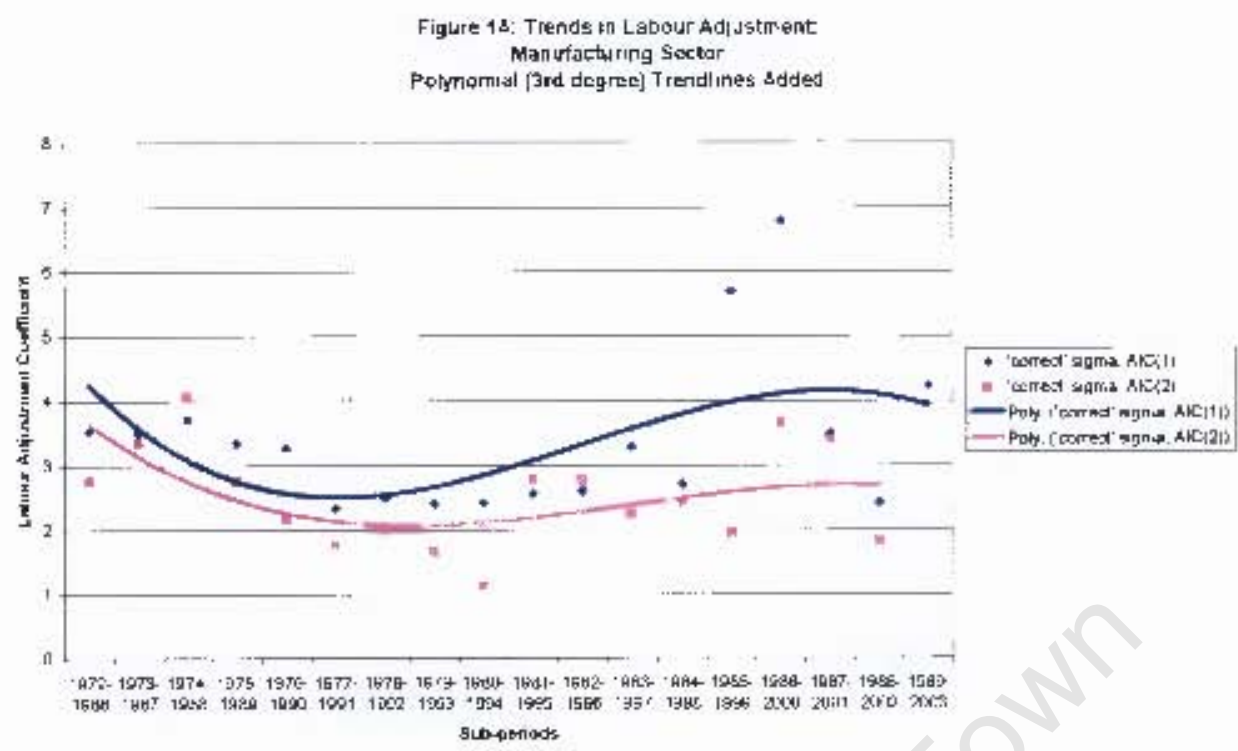

Figure 1B: Trands in Libaur Adjuxtrnert:

Manuracturing Sactor

Polynamual |3rd degrec| Trendlines stded

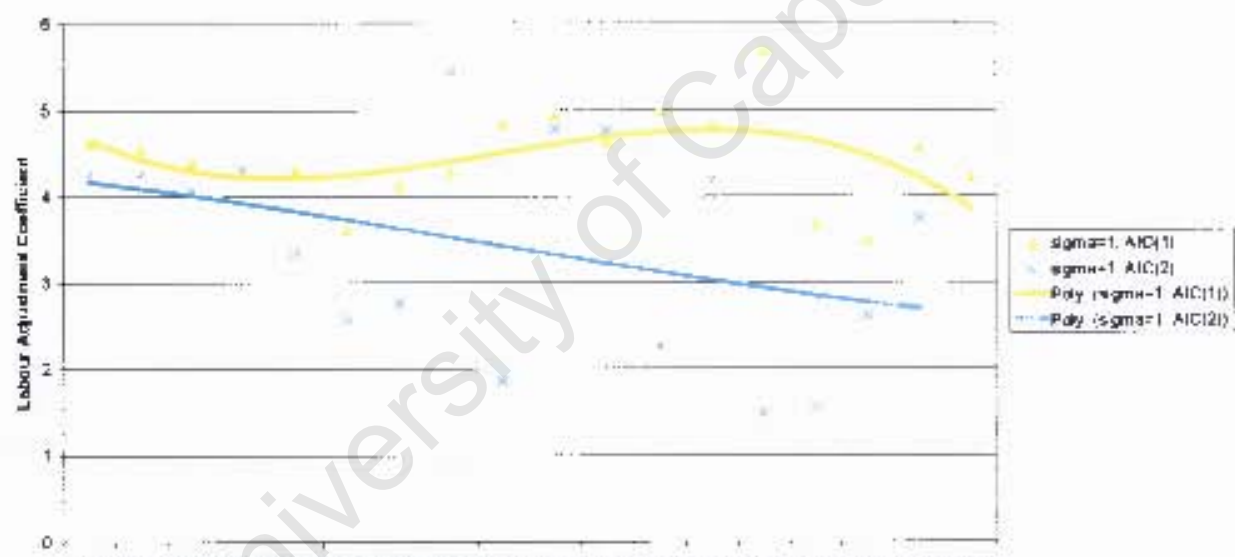

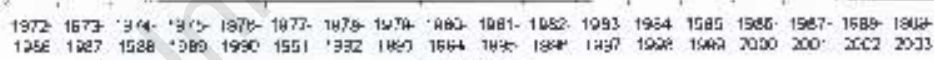
sub-ponoto 
Table 1A: Computed Mark-up - Moving Average

Manufacturing 3-digit Sectors

Food

Beverages

Tobacco

Textiles

Wearing apparel

Leather \& leather products

Footwear

Wood \& wood products

Paper \& paper products

Printing, publishing \& recorded media

Coke $\&$ refined petroleum

Basic chemicals

Other chemicals \& man-made fibers

Rubber products

Plastic products

Glass \& glass products

Non-metallic minerals

Basic iron \& steel

Basic non-ferrous metals

Metal products excluding machinery

Machinery \& equipment

Electrical machinery \& apparatus

Television, radio \& communication equipment

Professional \& scientific equipment

1971-

0.77

0.74

-1.48
-0.34

$-0.34$

0.17

0.08

0.07

0.49

0.59

0.22
-1.47

$-1.47$

1.11

0.28

0.39

0.75

0.29

0.45

0.09

$-0.06$

0.29

0.50

0.91

0.41

Motor vehicles, parts $\&$ accessories

ther transport equipment

Furniture

Other manufacturing

8

$1975-1984$
0.66
-0.18
0.85
0.29
0.18
0.11
0.08
0.56
0.72
0.25
1.92
0.70
0.56
0.41
0.69
0.35
0.48
0.37
0.51
0.27
0.28
0.79
0.48
0.51
0.20
0.12
-0.07
1.31

$1981-1990$
0.70
1.73
1.73
0.54
0.31
0.24
0.15
0.88
4.41
0.54
0.58
0.81
0.83
0.38
2.27
0.59
-0.70
0.35
1.28
0.59
0.41
0.49
-1.93
0.46
0.06
0.74
0.15
2.54

$\begin{array}{ccc}\mathbf{1 9 8 5 - 1 9 9 4} & \mathbf{1 9 9 1 - 2 0 0 0} & \mathbf{1 9 9 5 - 2 0 0 4} \\ 0.73 & 1.28 & 1.85 \\ 2.11 & 2.09 & 3.56 \\ -2.06 & -0.45 & -76.29 \\ 0.66 & 1.23 & 1.31 \\ 0.36 & -1.06 & -0.50 \\ 0.30 & 0.60 & -0.54 \\ 0.17 & -0.04 & 0.13 \\ 1.07 & 0.64 & 0.39 \\ 4.45 & 2.30 & 2.14 \\ 0.60 & -0.30 & -0.48 \\ 1.99 & -14.32 & -17.75 \\ 0.89 & 2.27 & 1.38 \\ 0.91 & 1.60 & 1.47 \\ 0.40 & 0.44 & -2073.24 \\ 2.30 & 0.59 & -0.60 \\ 0.66 & 0.69 & -2.51 \\ -0.73 & 1.98 & 3.56 \\ 0.36 & -0.26 & 2.18 \\ 1.47 & -5.19 & -7.48 \\ 0.33 & 0.41 & 1.54 \\ 0.53 & 0.01 & 0.23 \\ 0.29 & 0.29 & 0.36 \\ -0.94 & -2.37 & -4.36 \\ 0.85 & 1.60 & 2.33 \\ 0.30 & -1.95 & -0.80 \\ 0.46 & -2.43 & -3.00 \\ 0.20 & 0.03 & 0.12 \\ 3.30 & 5.07 & 4.44\end{array}$


Table 1B: Computed Mark-up - Moving Average of Smoothed Series

$\begin{array}{lcccccc}\text { Manufacturing 3-digit Sectors } & \mathbf{1 9 7 1 - 1 9 8 0} & \mathbf{1 9 7 5 - 1 9 8 4} & \mathbf{1 9 8 1 - 1 9 9 0} & \mathbf{1 9 8 5 - 1 9 9 4} & \mathbf{1 9 9 1 - 2 0 0 0} & \mathbf{1 9 9 5 - 2 0 0 4} \\ \text { Food } & 0.77 & 0.72 & 0.69 & 0.88 & 1.38 & 1.69 \\ \text { Beverages } & 0.71 & 0.65 & 1.75 & 2.15 & 2.61 & 3.52 \\ \text { Tobacco } & -1.52 & 1.57 & 1.09 & -1.83 & 12.58 & -77.07 \\ \text { Textiles } & -0.36 & 0.08 & 0.53 & 0.60 & 1.32 & 1.38 \\ \text { Wearing apparel } & 0.17 & 0.19 & 0.29 & 0.51 & 0.09 & -0.67 \\ \text { Leather \& leather products } & 0.08 & 0.12 & 0.23 & 0.41 & 0.23 & -0.65 \\ \text { Footwear } & 0.07 & 0.09 & 0.13 & 0.29 & 0.11 & 0.01 \\ \text { Wood \& wood products } & 0.48 & 0.58 & 0.88 & 1.15 & 0.61 & 0.31 \\ \text { Paper \& paper products } & 0.57 & 0.55 & 2.99 & 5.18 & 3.85 & 1.53 \\ \text { Printing, publishing \& recorded media } & 0.21 & 0.29 & 0.57 & 0.33 & -0.35 & -0.22 \\ \text { Coke \& refined petroleum } & -1.43 & 2.97 & 1.10 & 1.87 & -12.05 & -17.81 \\ \text { Basic chemicals } & 1.11 & 0.92 & 0.79 & 1.14 & 1.94 & 1.14 \\ \text { Other chemicals \& man-made fibers } & 0.26 & 0.56 & 0.84 & 0.86 & 2.51 & 1.51 \\ \text { Rubber products } & 0.50 & -0.07 & 2.16 & 59.26 & -837.79 & -2131.59 \\ \text { Plastic products } & 0.74 & 0.62 & 1.92 & 2.44 & 0.71 & -0.69 \\ \text { Glass \& glass products } & 0.28 & 0.38 & 0.61 & 0.77 & -0.05 & -2.64 \\ \text { Non-metallic minerals } & 0.48 & 0.57 & -0.64 & -0.72 & 1.99 & 3.54 \\ \text { Basic iron \& steel } & 0.08 & 0.27 & 0.36 & 0.34 & 0.18 & 2.20 \\ \text { Basic non-ferrous metals } & -0.09 & 0.50 & 1.38 & -0.27 & -4.24 & -5.72 \\ \text { Metal products excluding machinery } & 0.28 & 0.29 & 0.48 & 0.41 & 0.44 & 1.46 \\ \text { Machinery \& equipment } & 0.51 & 0.35 & 0.41 & 0.54 & 0.30 & 0.21 \\ \text { Electrical machinery \& apparatus } & 0.92 & 0.72 & 0.49 & 0.48 & 0.22 & 0.17 \\ \text { Television, radio \& communication equipment } & 0.46 & 0.43 & -1.35 & -1.23 & -2.71 & -4.03 \\ \text { Professional \& scientific equipment } & 0.46 & 0.44 & 0.45 & 0.83 & 1.86 & 2.38 \\ \text { Motor vehicles, parts \& accessories } & 0.22 & 0.19 & 0.13 & 0.22 & -2.27 & -0.70 \\ \text { Other transport equipment } & 0.88 & 0.24 & 0.72 & -0.24 & -2.21 & -2.32 \\ \text { Furniture } & -0.10 & -0.02 & 0.18 & 0.16 & -0.01 & 0.16 \\ \text { Other manufacturing } & 1.32 & 1.54 & 2.66 & 3.27 & 4.94 & 4.43\end{array}$


Table 1C: Computed Mark-up - Standard Deviation

Manufacturing 3-digit Sectors

Food

Beverages

Tobacco

Textiles

Wearing apparel

Leather \& leather products

Footwear

Wood \& wood products

Paper \& paper products

Printing, publishing \& recorded media

Coke $\&$ refined petroleum

Basic chemicals

Other chemicals \& man-made fibers

Rubber products

Plastic products

Glass \& glass products

Non-metallic minerals

Basic iron \& steel

Basic non-ferrous metals

Metal products excluding machinery

Machinery \& equipment

Electrical machinery \& apparatus

Professional \& scientific equipment 0.96

Motor vehicles, parts \& accessories $\quad 0.20$

Other transport equipment $\quad 2.39$

Furniture

Other manufacturing

$1971-1980$
0.54
5.00
10.64
1.91
0.18
0.08
0.06
0.67
0.51
0.20
11.47
1.38
0.63
0.29
0.83
0.16
0.54
1.01
1.10
0.21
0.69
1.24
0.53
0.96
0.20
2.39
0.55
1.97

$\begin{array}{cc}1975-1984 & 1981-199 \\ 0.23 & 0.14 \\ 3.70 & 1.68 \\ 8.31 & 8.22 \\ 0.21 & 0.52 \\ 0.10 & 0.29 \\ 0.09 & 0.10 \\ 0.04 & 0.12 \\ 0.41 & 0.64 \\ 0.39 & 11.34 \\ 0.09 & 0.63 \\ 2.74 & 7.31 \\ 0.45 & 0.41 \\ 0.28 & 0.61 \\ 0.13 & 0.23 \\ 0.71 & 5.01 \\ 0.11 & 0.49 \\ 0.29 & 4.25 \\ 0.22 & 0.14 \\ 0.63 & 0.97 \\ 0.14 & 0.65 \\ 0.26 & 0.43 \\ 1.19 & 0.19 \\ 0.47 & 7.79 \\ 0.93 & 0.39 \\ 0.17 & 2.21 \\ 1.12 & 1.05 \\ 0.54 & 0.31 \\ 1.94 & 1.74\end{array}$

$\begin{array}{ccc}\mathbf{1 9 8 5 - 1 9 9 4} & \mathbf{1 9 9 1 - 2 0 0 0} & \mathbf{1 9 9 5 - 2 0 0 4} \\ \mathbf{0 . 1 3} & 1.26 & 1.30 \\ 1.63 & 1.00 & 3.52 \\ 14.16 & 19.92 & 259.31 \\ 0.50 & 1.37 & 2.39 \\ 0.27 & 9.49 & 9.67 \\ 0.11 & 1.47 & 3.42 \\ 0.15 & 3.40 & 3.85 \\ 0.62 & 1.99 & 1.95 \\ 11.33 & 4.04 & 4.30 \\ 0.60 & 2.20 & 2.15 \\ 8.39 & 44.10 & 42.85 \\ 0.36 & 2.04 & 3.57 \\ 0.59 & 1.78 & 8.69 \\ 0.24 & 2.41 & 6555.49 \\ 5.00 & 1.28 & 4.00 \\ 0.49 & 0.76 & 7.70 \\ 4.23 & 3.71 & 4.39 \\ 0.12 & 1.44 & 6.33 \\ 0.94 & 13.78 & 18.53 \\ 1.22 & 1.19 & 2.33 \\ 0.41 & 1.96 & 2.10 \\ 1.16 & 2.65 & 2.40 \\ 8.70 & 9.44 & 8.53 \\ 0.91 & 2.05 & 4.76 \\ 2.24 & 19.30 & 20.27 \\ 1.35 & 5.56 & 5.76 \\ 0.32 & 1.61 & 1.67 \\ 1.92 & 1.89 & 2.95\end{array}$


Table 2: PMGE Results for Manufacturing Sector Mark-up

$\begin{array}{llllll} & \mu-1 & \Phi(E C M) & \text { h-test } & \text { RLL } & \text { LR } \\ 1971-2004 & 0.54^{\star} & -0.87^{\star} & 0.98 & 951.06 & 364.39 \\ & (0.02) & (0.07) & {[0.32]} & & {[0.00]} \\ 1971-1980 & 0.79^{\star} & -1.02^{\star} & 0.40 & 327.57 & 332.29 \\ & (0.02) & (0.06) & {[0.53]} & & {[0.00]} \\ 1975-1984 & 0.50^{\star} & -1.01^{\star} & 1.91 & 245.47 & 425.16 \\ & (0.01) & (0.02) & {[0.17]} & & {[0.00]} \\ 1981-1990 & 0.57^{\star} & -0.94^{\star} & 0.74 & 281.41 & 333.49 \\ & (0.01) & (0.04) & {[0.39]} & & {[0.00]} \\ 1985-1994 & 0.70^{\star} & -0.98^{\star} & 0.96 & 393.46 & 368.42 \\ & (0.01) & (0.09) & {[0.33]} & & {[0.00]} \\ 1991-2000 & 0.50^{\star} & -1.12^{\star} & 1.93 & 258.80 & 122.53 \\ & (0.03) & (0.08) & {[0.16]} & & {[0.00]} \\ 1995-2004 & 0.62^{\star} & -1.05^{\star} & 0.98 & 228.63 & 91.16 \\ & (0.06) & (0.06) & {[0.32]} & & {[0.00]}\end{array}$

Note: * denotes significance at the $5 \%$ level, (s.e.), [p-value] 
Table 3: ADF Test Statistic

Variable:

(using AIC(5) to select lag order)

NSR

I(0)

Food

$-4.66$

Beverages

$-4.67$

Tobacco

$-5.07$

Textiles

$-3.95$

Wearing apparel

$-4.03$

Leather \& leather products

$-4.55$

Footwear

$-3.00$

Wood \& wood products

$-4.67$

$-4.10$

$-4.55$

Printing, publishing \& recorded media

$-5.62$

Coke $\&$ refined petroleum

$-5.62$

$-4.76$

Other chemicals \& man-made fibers

$-4.67$

Rubber products

-4.67
-3.91

$-3.57$

Glass \& glass products

Non-metallic minerals

Basic iron \& steel

$-3.81$

$-2.77^{\star}$

$-5.02$

ROEGER

I(1) I(0) I(1)

$-5.45$

$-5.35$

$-6.61$

$-5.84$

$-5.78$

$-5.82$

$-5.61$

$-5.16$

$-4.71$

$-4.54$

$-5.55$

$-5.98$

$-5.84$

$-4.80$

$-4.86$

$-5.59$

$-5.44$

Basic non-ferrous metals

$-4.41$

$-6.48 \quad-5.64$

Metal products excluding machinery

Machinery \& equipment

$-4.92$

$-5.20$

$-5.52$

$-5.46$

Electrical machinery \& apparatus

Television, radio \& communication equipment

Professional \& scientific equipment

$-4.47$

$-4.77$

$-4.94$

$-7.31$

$\begin{array}{ll}-3.26 & -5.31\end{array}$

Motor vehicles, parts \& accessories

$-5.07$

$-4.21$

Other transport equipment

$-3.93$

$-5.32$

Other manufacturing

$-5.62$

$-5.73$

Note: * denotes test statistic that is greater than the critical value 
Table 4: Estimated Mark-up

Manufacturing 3-digit Sectors

Food

Beverages

Tobacco

Textiles

Wearing apparel

Leather \& leather products

Footwear

Wood \& wood products

Paper \& paper products

Printing, publishing \& recorded media

Coke \& refined petroleum

Basic chemicals

Other chemicals \& man-made fibers

Rubber products

Plastic products

Glass \& glass products

Non-metallic minerals

Basic iron \& steel

Basic non-ferrous metals

Metal products excluding machinery

Machinery \& equipment

Electrical machinery \& apparatus

Television, radio $\&$ communication equipment

Professional \& scientific equipment

Motor vehicles, parts \& accessories

Other transport equipment

Furniture

Other manufacturing

$\begin{array}{ccc}1971-2004 & \text { (s.e.) } & 1971-1980 \\ 0.86^{\star} & (0.10) & 0.79 \\ 1.07^{\star} & (0.12) & 1.45 \\ 4.05^{\star} & (0.58) & 4.27 \\ 0.51^{\star} & (0.06) & 0.49 \\ 0.29^{\star} & (0.07) & 0.35 \\ 0.16^{\star} & (0.03) & 0.17 \\ 0.14^{\star} & (0.04) & 0.10 \\ 0.55^{\star} & (0.06) & 0.93 \\ 0.84^{\star} & (0.09) & 0.17 \\ 0.28^{\star} & (0.06) & 0.35 \\ 3.31^{\star} & (0.60) & 1.55 \\ 0.83^{\star} & (0.11) & 0.89 \\ 0.70^{\star} & (0.06) & 0.40 \\ 0.52^{\star} & (0.06) & 0.58 \\ 0.69^{\star} & (0.09) & 0.45 \\ { }^{\star} & & 0.28 \\ 0.96^{\star} & (0.25) & 0.70 \\ 0.60^{\star} & (0.11) & 0.54 \\ 0.77^{\star} & (0.12) & 2.75 \\ 0.41^{\star} & (0.05) & 0.44 \\ 0.29^{\star} & (0.05) & 0.14 \\ 0.49^{\star} & (0.05) & 0.93 \\ 0.46^{\star} & (0.05) & 0.28 \\ 0.52^{\star} & (0.06) & 0.74 \\ 0.39^{\star} & (0.10) & 0.46 \\ 0.36^{\star} & (0.08) & 0.70 \\ 0.20^{\star} & (0.03) & 0.42 \\ 2.16^{\star} & (0.19) & 3.12\end{array}$

1975
0.87
1.47
0.73
0.56
0.29
0.13
0.14
0.79
0.81
0.39
2.90
0.79
0.93
0.60
0.75
0.40
0.79
0.54
1.35
0.46
0.23
0.72
0.39
0.61
0.42
0.49
0.28
2.00

$\begin{array}{ccccc}\mathbf{1 9 7 5 - 1 9 8 4} & \mathbf{1 9 8 1 - 1 9 9 0} & \mathbf{1 9 8 5 - 1 9 9 4} & \mathbf{1 9 9 1 - 2 0 0 0} & \mathbf{1 9 9 5 - 2 0 0 4} \\ \mathbf{0 . 8 7} & 0.61 & 0.70 & 0.68 & 1.08 \\ 1.47 & 0.97 & 1.30 & 1.17 & 2.29 \\ 0.73 & 5.03 & 3.79 & 2.16 & -7.79 \\ 0.56 & 0.30 & 0.39 & 0.82 & 1.26 \\ 0.29 & 0.19 & 0.26 & 0.24 & 0.63 \\ 0.13 & 0.21 & 0.26 & 0.07 & -0.25 \\ 0.14 & 0.10 & 0.15 & -0.69 & 0.47 \\ 0.79 & 0.59 & 0.77 & -0.24 & 0.22 \\ 0.81 & 0.73 & 0.81 & 1.02 & 1.19 \\ 0.39 & 0.31 & 0.45 & 1.19 & 0.07 \\ 2.90 & 2.93 & 2.98 & 4.74 & 2.12 \\ 0.79 & 0.34 & 0.84 & 5.05 & 0.59 \\ 0.93 & 0.61 & 0.76 & 0.29 & 0.29 \\ 0.60 & 0.42 & 0.48 & 0.03 & 0.07 \\ 0.75 & 0.50 & 0.56 & 1.82 & 0.85 \\ 0.40 & 0.58 & 0.65 & 0.84 & 1.36 \\ 0.79 & 0.58 & 0.62 & 0.29 & 1.03 \\ 0.54 & 0.24 & 0.24 & 0.24 & 1.52 \\ 1.35 & 0.76 & 1.16 & 0.62 & 1.55 \\ 0.46 & 0.32 & 0.40 & 0.30 & 0.79 \\ 0.23 & 0.25 & 0.39 & 0.36 & 0.27 \\ 0.72 & 0.45 & 0.62 & 0.38 & -0.01 \\ 0.39 & 0.44 & 0.42 & 0.53 & 0.52 \\ 0.61 & 0.53 & 0.82 & 0.98 & 1.12 \\ 0.42 & 0.19 & 0.51 & 0.74 & 1.41 \\ 0.49 & 0.46 & 0.50 & -0.04 & 0.11 \\ 0.28 & 0.18 & 0.26 & 0.30 & 0.42 \\ 2.00 & 2.09 & 3.28 & 5.73 & 4.50\end{array}$

Note: * denotes significance at the $5 \%$ level, ${ }^{\star \star}$ denotes case in which statistically reliable results were not available 
Table 5: Summary of Recent Mark-up Behaviour

Change in mark-up from 1991-2000 to $1995-2004$

Level of mark-up in 1991-

\begin{tabular}{|c|c|c|c|}
\hline 2000 & Increase & Decrease & Less than $10 \%$ change \\
\hline $\begin{array}{l}\text { High } \\
\text { (above 80\%) }\end{array}$ & $\begin{array}{l}\text { Beverages } \\
\text { Textiles } \\
\text { Paper \& paper products } \\
\text { Glass \& glass products } \\
\text { Professional \& scientific equipment } \\
\text { Furniture }\end{array}$ & $\begin{array}{l}\text { Tobacco } \\
\text { Printing, publishing \& recorded } \\
\text { media } \\
\text { Coke \& refined petroleum } \\
\text { Basic chemicals } \\
\text { Plastic products } \\
\text { Other manufacturing } \\
\end{array}$ & \\
\hline Medium & $\begin{array}{l}\text { Food } \\
\text { Basic non-ferrous metals }{ }^{\star \star} \\
\text { Motor vehicles, parts \& } \\
\text { accessories }\end{array}$ & 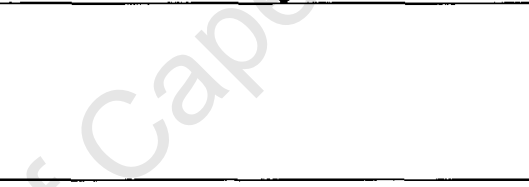 & $\begin{array}{l}\text { Television, radio \& communication } \\
\text { equipment }\end{array}$ \\
\hline $\begin{array}{l}\text { Low } \\
\text { (below 40\%) }\end{array}$ & $\begin{array}{l}\text { Wearing apparel } \\
\text { Footwear } \\
\text { Wood \& wood products* } \\
\text { Non-metallic minerals } \\
\text { Basic iron and steel } \\
\text { Metal products excluding } \\
\text { machinery } \\
\text { Other transport equipment }\end{array}$ & Leather \& leather products & $\begin{array}{l}\text { Other chemicals \& man-made fibers } \\
\text { Rubber products } \\
\text { Machinery \& equipment }\end{array}$ \\
\hline
\end{tabular}


Table 6: Model Specification and Diagnostics Manufacturing 3-digit Sectors

Food

Beverages

Tobacco

Textiles

Wearing appare

Leather \& leather products

Footwear

Wood \& wood products

Paper \& paper products

Printing, publishing \& recorded media

Coke $\&$ refined petroleum

Basic chemicals

Other chemicals \& man-made fibers

Rubber products

Plastic products

Glass \& glass products

Non-metallic minerals

Basic iron \& steel

Basic non-ferrous metals

Metal products excluding machinery

Machinery \& equipment

Electrical machinery \& apparatus

Television, radio \& communication equipment

Professional \& scientific equipment

Motor vehicles, parts \& accessories

Other transport equipment

Furniture

Other manufacturing

Note: * denotes significance at the $5 \%$ level, [p-value]
Lag Structure:

Imposed

2,0

1,0

1,0

1,2

2,1
1,0

2,0

1,0

1,2

1,1

1,1

1,0
1,1

1,2

2,0

2,1

2,2

2,0

1,0

1,2

1,0

1,1

1,0

1,2

1,2
1,0

1,0

\section{Diagnostics (LM version):}

Serial Correlation Functional Form Normality Heteroscedasticity

\begin{tabular}{|c|c|c|c|c|c|c|c|}
\hline 0.38 & {$[.54]$} & 0.03 & {$[.86]$} & 1.15 & [.56] & 1.00 & [.32] \\
\hline 0.61 & [.43] & 0.16 & [.69] & 2.69 & [.26] & 0.00 & {$[.98]$} \\
\hline 0.46 & [.50] & 0.31 & [.58] & 1.11 & [.57] & 1.40 & {$[.24]$} \\
\hline 0.01 & [.92] & 1.45 & [.23] & 2.68 & [.26] & 0.05 & [.83] \\
\hline 0.04 & & 0.01 & {$[.91]$} & 0.57 & {$[.75]$} & 0.18 & {$[.67]$} \\
\hline 1.47 & {$[.23]$} & 2.21 & [.14] & 4.70 & [.10] & 0.69 & [.41] \\
\hline 0.33 & [.57] & 0.69 & {$[.41]$} & 3.51 & {$[.17]$} & 0.45 & {$[.51]$} \\
\hline 0.02 & {$[.90]$} & 0.03 & {$[.87]$} & 0.12 & {$[.94]$} & 0.06 & {$[.80]$} \\
\hline 0.45 & [.50] & 0.12 & [.73] & 3.59 & {$[.17]$} & 0.50 & {$[.48]$} \\
\hline 0.52 & {$[.47]$} & 0.85 & [.36] & 0.11 & {$[.95]$} & 0.70 & {$[.40]$} \\
\hline 0.00 & {$[.96]$} & 0.20 & [.65] & 0.81 & [.67] & 0.46 & {$[.50]$} \\
\hline 1.25 & {$[.26]$} & 1.15 & [.28] & 1.70 & {$[.43]$} & 1.21 & {$[.27]$} \\
\hline 0.58 & {$[.45]$} & 2.38 & [.12] & 0.50 & [.78] & 0.15 & {$[.70]$} \\
\hline 3.25 & {$[.07]$} & 0.51 & [.48] & 0.53 & {$[.77]$} & 2.42 & [.12] \\
\hline 0.23 & [.63] & 0.00 & {$[.97]$} & 0.35 & {$[.84]$} & 0.27 & {$[.60]$} \\
\hline $6.20^{\star}$ & {$[.01]$} & 0.76 & {$[.39]$} & 0.85 & [.65] & 0.00 & {$[.96]$} \\
\hline 0.44 & {$[.51]$} & 0.46 & {$[.50]$} & 2.71 & {$[.26]$} & 0.85 & {$[.36]$} \\
\hline 0.68 & [.41] & 1.23 & {$[.27]$} & 0.36 & [.83] & 0.69 & {$[.41]$} \\
\hline 0.00 & [.95] & 0.89 & [.35] & 3.08 & [.21] & 0.94 & [.33] \\
\hline 0.08 & {$[.78]$} & 0.25 & {$[.62]$} & 0.17 & {$[.92]$} & 0.63 & [.43] \\
\hline 0.13 & {$[.71]$} & 0.76 & [.38] & 2.80 & [.25] & 0.10 & {$[.76]$} \\
\hline 0.00 & {$[1.00]$} & 0.27 & {$[.60]$} & 0.96 & {$[.62]$} & 2.70 & {$[.10]$} \\
\hline 0.97 & [.33] & 0.02 & [.89] & 3.95 & {$[.14]$} & 0.04 & {$[.83]$} \\
\hline 1.00 & [.32] & 0.07 & [.79] & 0.24 & {$[.89]$} & 0.87 & {$[.35]$} \\
\hline 0.02 & {$[90]$} & 0.35 & {$[.55]$} & 1.08 & [.58] & 0.05 & [.82] \\
\hline 0.01 & [.93] & 0.55 & {$[.46]$} & 0.25 & [.88] & 0.02 & {$[.89]$} \\
\hline 1.48 & [.22] & 0.37 & [.54] & 2.10 & {$[.35]$} & 0.01 & {$[.91]$} \\
\hline
\end{tabular}


Table 7: PMGE Results for Manufacturing Sector Labour Adjustment

$1972-2004 \quad \beta 1 \quad \beta 2 \quad \sigma$-hat $\quad$ Lab adj ( $\sigma$-hat) Lab adj $(\sigma=1)$

$\begin{array}{llllll}\text { AIC(1) } & 0.42^{\star} & -4.88^{\star} & 0.70 & 3.43 & 4.88\end{array}$

$\begin{array}{llllll}\text { AIC(2) } & (0.15) & (0.15) & & & \\ 0.67^{\star} & -4.74^{\star} & 0.60 & 2.84 & 4.74\end{array}$

$\begin{array}{llllll}\text { AIC(3) } & (0.14) & (0.15) & & & \\ & 0.59^{*} & -4.76^{*} & 0.63 & 2.99 & 4.76\end{array}$

(0.14) (0.15)

Note: * denotes significance at the $5 \%$ level

Table 8: PMGE Results for Manufacturing Sector Labour Adjustment

\begin{tabular}{lllll} 
& \multicolumn{2}{l}{ Lab adj ("correct" $\sigma)^{\star}$} & \multicolumn{2}{l}{ Lab adj $(\sigma=1)$} \\
Sub-period & AlC(1) & AlC (2) & AlC(1) & AIC(2) \\
$1972-1986$ & 3.54 & 2.76 & 4.63 & 4.25 \\
$1973-1987$ & 3.51 & 3.36 & 4.56 & 4.27 \\
$1974-1988$ & 3.71 & 4.06 & 4.40 & 4.06 \\
$1975-1989$ & 3.35 & 2.75 & 4.34 & 4.33 \\
$1976-1990$ & 3.28 & 2.17 & 4.32 & 3.35 \\
$1977-1991$ & 2.35 & 1.75 & 3.61 & 2.59 \\
$1978-1992$ & 2.50 & 2.02 & 4.13 & 2.77 \\
$1979-1993$ & 2.42 & 1.68 & 4.29 & 5.46 \\
$1980-1994$ & 2.43 & 1.13 & 4.84 & 1.87 \\
$1981-1995$ & 2.58 & 2.80 & 4.94 & 4.79 \\
$1982-1996$ & 2.62 & 2.78 & 4.63 & 4.77 \\
$1983-1997$ & 3.29 & 2.27 & 5.00 & 2.27 \\
$1984-1998$ & 2.72 & 2.43 & 4.84 & 4.19 \\
$1985-1999$ & 5.69 & 1.96 & 5.69 & 1.50 \\
$1986-2000$ & 6.79 & 3.66 & 3.69 & 1.56 \\
$1987-2001$ & 3.50 & 3.40 & 3.50 & 2.62 \\
$1988-2002$ & 2.45 & 1.83 & 4.58 & 3.76 \\
$1989-2003$ & 4.23 & $\star \star$ & 4.23 & $\star \star$ \\
$1990-2004$ & $\star \star$ & $\star \star$ & $\star \star$ & $\star \star$
\end{tabular}

* See text for interpretation of "correct"

** Statistically reliable results not available 
Table 9: PSS ARDL Results for Manufacturing Sector Labour Adjustment

\begin{tabular}{|c|c|c|c|c|c|c|}
\hline $1972-2004$ & $\beta 1$ & $\beta 2$ & $\sigma$-hat & Lab adj ( $\sigma$-hat) & Lab adj $(\sigma=1)$ & $\begin{array}{l}\text { Lab adj } \\
\text { ("correct" } \sigma \text { ) }\end{array}$ \\
\hline Food & $\begin{array}{l}0.13 \\
(0.25)\end{array}$ & $\begin{array}{l}-2.86^{*} \\
(0.31)\end{array}$ & 0.88 & 2.52 & 2.86 & 2.86 \\
\hline$B e v e^{\star \star}$ & $\begin{array}{l}0.29 \\
(0.26)\end{array}$ & $\begin{array}{l}-1.24^{*} \\
(0.16)\end{array}$ & 0.78 & 0.96 & 1.24 & 1.24 \\
\hline Toba & $\mathrm{n} / \mathrm{a}$ & & & & & \\
\hline $\operatorname{Text} t^{* \star \star}$ & $\begin{array}{l}5.82 \\
(3.23)\end{array}$ & $\begin{array}{l}-8.99^{*} \\
(2.00)\end{array}$ & 0.15 & 1.32 & 8.99 & 8.99 \\
\hline Wear & $\begin{array}{l}0.31 \\
(1.76)\end{array}$ & $\begin{array}{l}-5.13^{*} \\
(1.95)\end{array}$ & 0.76 & 3.91 & 5.13 & 5.13 \\
\hline Leat** & $\begin{array}{l}-2.32 \\
(1.46)\end{array}$ & $\begin{array}{l}-5.37^{\star} \\
(0.91)\end{array}$ & -0.76 & -4.07 & 5.37 & 5.37 \\
\hline Foot & $\begin{array}{l}7.93^{\star} \\
(3.40)\end{array}$ & $\begin{array}{l}-9.95^{\star} \\
(1.86)\end{array}$ & 0.11 & 1.11 & 9.95 & 1.11 \\
\hline Wood & $\begin{array}{l}0.99 \\
(0.68)\end{array}$ & $\begin{array}{l}-2.97^{\star} \\
(0.88)\end{array}$ & 0.50 & 1.50 & 2.97 & 2.97 \\
\hline Pape & $\mathrm{n} / \mathrm{a}$ & & & & & \\
\hline Prin & $\begin{array}{l}-0.27 \\
(0.35)\end{array}$ & $\begin{array}{l}-2.11^{\star} \\
(1.00)\end{array}$ & 1.37 & 2.88 & 2.11 & 2.11 \\
\hline Coke & $\begin{array}{l}-0.22 \\
(0.22)\end{array}$ & $\begin{array}{l}-1.27^{\star} \\
(0.44)\end{array}$ & 1.29 & 1.64 & 1.27 & 1.27 \\
\hline Chem & $\begin{array}{l}0.23 \\
(0.23)\end{array}$ & $\begin{array}{l}-1.55^{\star} \\
(0.26)\end{array}$ & 0.81 & 1.26 & 1.55 & 1.55 \\
\hline Otch & $n / a$ & & & & & \\
\hline Rubb*** & $\begin{array}{l}8.27 \\
(5.39)\end{array}$ & $\begin{array}{l}-7.18^{*} \\
(2.63)\end{array}$ & 0.11 & 0.77 & 7.18 & 7.18 \\
\hline Plas ${ }^{\star \star \star}$ & $\begin{array}{l}1.45^{\star} \\
(0.57)\end{array}$ & $\begin{array}{l}-3.79^{*} \\
(0.77)\end{array}$ & 0.41 & 1.54 & 3.79 & 1.54 \\
\hline $\begin{array}{l}\text { Glas }{ }^{\star \star} \\
\text { Nmet }\end{array}$ & $\begin{array}{l}0.01 \\
(0.81) \\
\mathrm{n} / \mathrm{a}\end{array}$ & $\begin{array}{l}-6.93^{\star} \\
(1.40)\end{array}$ & 0.99 & 6.85 & 6.93 & 6.93 \\
\hline Iron** & $\begin{array}{l}1.25^{\star} \\
(0.28)\end{array}$ & $\begin{array}{l}-4.32^{\star} \\
(0.34)\end{array}$ & 0.45 & 1.92 & 4.32 & 1.92 \\
\hline Nfer & $n / a$ & 8 & & & & \\
\hline Meta & $\begin{array}{l}-0.59 \\
(0.47)\end{array}$ & $\begin{array}{l}-5.36^{*} \\
(0.34)\end{array}$ & 2.45 & 13.10 & 5.36 & 5.36 \\
\hline $\operatorname{Mach}^{\star \star}$ & $\begin{array}{l}-0.56 \\
(0.42)\end{array}$ & $\begin{array}{l}-4.90^{\star} \\
(0.56)\end{array}$ & 2.28 & 11.19 & 4.90 & 4.90 \\
\hline Elec $^{\star \star}$ & $\begin{array}{l}-0.81 \\
(0.57)\end{array}$ & $\begin{array}{l}-2.84^{\star} \\
(0.45)\end{array}$ & 5.37 & 15.25 & 2.84 & 2.84 \\
\hline Tele & $\mathrm{n} / \mathrm{a}$ & & & & & \\
\hline Prof & $\begin{array}{l}-0.97 \\
(0.58)\end{array}$ & $\begin{array}{l}-3.41^{\star} \\
(0.31)\end{array}$ & 33.50 & 114.36 & 3.41 & 3.41 \\
\hline Moto ${ }^{\star \star \star}$ & $\begin{array}{l}3.24 \\
(2.32)\end{array}$ & $\begin{array}{l}-8.61^{\star} \\
(3.69)\end{array}$ & 0.24 & 2.03 & 8.61 & 8.61 \\
\hline Ottr & $\mathrm{n} / \mathrm{a}$ & & & & & \\
\hline Furn & $\begin{array}{l}-0.80 \\
(0.63)\end{array}$ & $\begin{array}{l}-7.36^{\star} \\
(0.59)\end{array}$ & 4.93 & 36.28 & 7.36 & 7.36 \\
\hline Otma & $\mathrm{n} / \mathrm{a}$ & & & & & \\
\hline
\end{tabular}

Note: * denotes significance at the $5 \%$ level, ${ }^{\star \star}$ denotes sector in which time dummies were used, ${ }^{\star \star \star}$ denotes sector in which some diagnostics were problematic, although still workable 
Table 10: Summary of Manufacturing Sector Labour Adjustment

\begin{tabular}{llllll}
\multicolumn{2}{l}{ Top third (most rigid) } & \multicolumn{2}{l}{ Middle third } & \multicolumn{2}{l}{ Bottom third (least rigid) } \\
Text & 8.99 & Food & 2.86 & Beve & 1.24 \\
Leat & 5.37 & Wear & 5.13 & Foot & 1.11 \\
Rubb & 7.18 & Wood & 2.97 & Coke & 1.27 \\
Glas & 6.93 & Prin & 2.11 & Chem & 1.55 \\
Meta & 5.36 & Mach & 4.90 & Plas & 1.54 \\
Moto & 8.61 & Elec & 2.84 & Iron & 1.92 \\
Furn & 7.36 & Prof & 8.61 & &
\end{tabular}


Table 11: MGE Results for Manufacturing Sector Labour Adjustment

\begin{tabular}{|c|c|c|c|c|c|c|c|c|c|c|c|c|c|c|c|c|c|c|}
\hline Sub-period & $\begin{array}{c}\text { Food } \\
\sigma=1\end{array}$ & $\begin{array}{l}\text { Text } \\
\sigma=1\end{array}$ & $\begin{array}{c}\text { Wear } \\
\sigma=1\end{array}$ & $\begin{array}{l}\text { Leat } \\
\sigma=1\end{array}$ & $\begin{array}{c}\text { Foot } \\
\sigma=1\end{array}$ & $\begin{array}{c}\text { Wood } \\
\sigma=1\end{array}$ & $\begin{array}{c}\text { Pape } \\
\sigma=1\end{array}$ & $\begin{array}{l}\text { Prin } \\
\sigma=1\end{array}$ & $\begin{array}{l}\text { Chem } \\
\text { var } \sigma\end{array}$ & $\begin{array}{l}\text { Otch } \\
\sigma=1\end{array}$ & $\begin{array}{l}\text { Plas } \\
\sigma=1\end{array}$ & $\begin{array}{c}\text { Glas } \\
\sigma=1\end{array}$ & $\begin{array}{l}\text { Iron } \\
\text { var } \sigma\end{array}$ & $\begin{array}{c}\text { Meta } \\
\sigma=1\end{array}$ & $\begin{array}{c}\text { Mach } \\
\sigma=1\end{array}$ & $\begin{array}{l}\text { Elec } \\
\sigma=1\end{array}$ & $\begin{array}{l}\text { Prof } \\
\sigma=1\end{array}$ & $\begin{array}{l}\text { Furn } \\
\sigma=1\end{array}$ \\
\hline $1972-1986$ & 3.34 & 2.79 & 9.42 & 13.99 & 17.87 & & 7.04 & 4.31 & 1.85 & & 4.33 & 5.19 & 4.09 & 5.65 & 6.88 & 3.77 & 4.82 & 11.98 \\
\hline $1973-1987$ & 3.15 & 2.78 & 9.61 & 11.90 & 17.84 & & 5.49 & 4.43 & 1.92 & & 4.34 & 5.22 & 2.77 & 5.54 & 7.09 & 3.95 & 4.75 & 11.73 \\
\hline $1974-1988$ & 3.41 & 3.47 & 6.99 & 16.50 & 17.93 & & 4.88 & 4.59 & 1.68 & & 4.68 & 4.93 & 2.87 & 5.48 & 7.19 & 4.03 & 4.66 & 11.76 \\
\hline $1975-1989$ & 3.04 & 4.23 & & 15.83 & 18.01 & & 5.42 & 4.30 & 1.70 & & 4.80 & 4.82 & 1.89 & 4.94 & 7.32 & 3.76 & 4.63 & 11.68 \\
\hline $1976-1990$ & 2.56 & 2.18 & & 15.28 & 16.55 & 4.19 & 5.18 & & 1.77 & & 4.74 & 4.57 & 1.49 & 4.82 & 6.99 & 3.10 & 4.10 & 11.58 \\
\hline $1977-1991$ & 3.07 & 5.69 & 4.32 & & 15.14 & 3.21 & 3.35 & 5.14 & 1.92 & 1.67 & & 3.58 & 1.43 & 4.79 & 5.79 & 3.23 & 4.79 & 9.99 \\
\hline $1978-1992$ & 3.59 & 5.61 & 6.47 & 6.51 & 9.39 & 3.07 & 2.33 & 4.45 & 1.86 & 1.84 & 4.05 & 3.30 & 1.15 & 4.92 & 5.74 & 3.21 & 5.32 & 8.36 \\
\hline $1979-1993$ & 3.75 & 5.28 & 7.32 & 7.91 & 13.96 & 2.48 & 1.80 & 4.49 & 1.88 & 2.04 & 3.91 & 2.56 & 1.12 & 5.27 & 5.69 & 3.32 & 2.85 & 8.48 \\
\hline $1980-1994$ & 2.14 & 5.15 & 7.03 & 9.48 & 13.80 & 2.09 & 1.48 & 4.15 & 1.67 & 3.58 & 3.28 & 2.93 & & 5.40 & 5.92 & 5.01 & 2.24 & 8.48 \\
\hline $1981-1995$ & 1.54 & 5.00 & 6.96 & 9.41 & 12.84 & 2.16 & & 1.44 & 1.89 & 2.72 & 3.53 & & & 5.07 & 5.25 & 5.25 & 2.20 & 7.63 \\
\hline $1982-1996$ & 1.65 & 5.00 & 12.41 & 2.78 & 12.37 & 1.60 & & 2.11 & 3.40 & 2.80 & 3.18 & 1.91 & & 4.65 & 6.15 & 3.26 & 3.31 & 8.75 \\
\hline $1983-1997$ & 2.22 & 5.58 & 11.64 & 5.28 & 12.20 & 1.77 & 1.48 & 3.76 & & 2.86 & 1.02 & 4.03 & 1.18 & 4.60 & 5.48 & 2.93 & 3.46 & 8.61 \\
\hline 1984-1998 & 4.13 & 8.34 & 10.53 & 5.42 & 12.24 & 1.21 & 1.76 & 4.27 & 5.52 & 2.76 & & & & 4.59 & 5.36 & 2.86 & & 10.13 \\
\hline 1985-1999 & 4.01 & 8.38 & 4.66 & 6.06 & 10.78 & 1.31 & 1.95 & 2.76 & 2.74 & 2.03 & 1.20 & & 2.33 & 6.46 & 9.98 & 2.66 & 6.29 & 9.09 \\
\hline $1986-2000$ & 3.63 & 8.75 & & 6.18 & 6.43 & 1.40 & 1.91 & 3.80 & 3.75 & 1.77 & 4.16 & & 1.70 & 6.56 & 6.77 & 2.08 & 6.06 & 9.04 \\
\hline $1987-2001$ & 2.63 & 10.70 & & 5.15 & 8.88 & & & & 2.24 & 4.38 & & & 1.68 & 6.39 & 5.35 & 2.24 & 6.07 & 9.20 \\
\hline
\end{tabular}

